NBER WORKING PAPER SERIES

\title{
THE PERVERSE EFFECTS OF PARTIAL LABOR MARKET REFORM: FIXED DURATION CONTRACTS IN FRANCE
}

\author{
Olivier Blanchard \\ Augustin Landier \\ Working Paper 8219 \\ http://www.nber.org/papers/w8219 \\ NATIONAL BUREAU OF ECONOMIC RESEARCH \\ 1050 Massachusetts Avenue \\ Cambridge, MA 02138 \\ April 2001
}

MIT and NBER, and MIT respectively. We thank Larry Katz for discussions, Francis Kramarz for help, and Daron Acemoglu, David Autor, Daniel Cohen, Michael Piore, and Peter Diamond for comments. The views expressed herein are those of the authors and not necessarily those of the National Bureau of Economic Research.

(C) 2001 by Olivier Blanchard and Augustin Landier. All rights reserved. Short sections of text, not to exceed two paragraphs, may be quoted without explicit permission provided that full credit, including (C) notice, is given to the source. 
The Perverse Effects of Partial Labor Market Reform:

Fixed Duration Contracts in France

Olivier Blanchard and Augustin Landier

NBER Working Paper No. 8219

April 2001

JEL No. J60, J63, J64, J68

\begin{abstract}
Rather than decrease firing costs across the board, a number of European countries have allowed firms to hire workers on fixed-duration contracts. At the end of a given duration, these contracts can be terminated at little or no cost. If workers are kept on however, the contracts become subject to regular firing costs. We argue in this paper that the effects of such a partial reform of employment protection may be perverse. The main effect may be high turnover in fixed-duration jobs, leading in turn to higher, not lower, unemployment. And, even if unemployment comes down, workers may actually be worse off, going through many spells of unemployment and fixed duration jobs, before obtaining a regular job. Looking at French data for young workers since the early 1980s, we conclude that the reforms have substantially increased turnover, without a substantial reduction in unemployment duration. If anything, their effect on welfare of young workers appears to have been negative.
\end{abstract}

Olivier Blanchard

Department of Economics

Massachusetts Institute of Technology

E52-373

50 Memorial Drive

Cambridge, MA 02138
Augustin Landier Department of Economics Massachusetts Institute of Technology 50 Memorial Drive

Cambridge, MA 02138 
There is now substantial evidence that high employment protection leads to a sclerotic labor market, with low separation rates but long unemployment duration. ${ }^{1}$ While this sclerosis may not lead to high unemploymentbecause of the opposite effects of low flows and high duration on the unemployment rate - it is likely to lead to both lower productivity, lower output, and lower welfare.

Broad reductions in employment protection run however into strong political opposition. The reason is simple: Those who are currently protected see themselves as having more to lose than to gain from such a reduction. For this reason, governments have either done little, or have tried to reform at the margin, allowing for reduced protection, but only for (some) new contracts. In France for example, firms now can, under some conditions, hire workers for a fixed duration, at the end of which separation occurs with low separation costs. If workers are kept beyond this fixed duration however, later separation becomes subject to normal firing costs.

Are such partial reforms better than none? The motivation for this paper was our suspicion that the answer might actually be negative, that the effects of such a partial reform might be perverse, leading to higher unemployment, lower output, and lower welfare for workers. Our intuition was as follows:

- Think of firms as hiring workers in entry-level jobs, finding out how good the matches are, and then deciding whether or not to keep the workers in higher productivity, regular, jobs.

- Now think of reform as lowering firing costs for entry-level jobs while keeping them the same for regular jobs. This will have two effects: It will make firms more willing to hire new workers, and see how they

\footnotetext{
${ }^{1}$ See OECD [1999], and Blanchard and Portugal [2001].
} 
perform. But, second, it will make firms more reluctant to keep them in regular jobs: Even if a match turns out to be quite productive, a firm may still prefer to fire the worker while the firing cost is low, and take a chance with a new worker.

- One may therefore worry that the result of such a reform may be more low productivity entry-level jobs, fewer regular jobs, and so lower overall productivity and output. Higher turnover in entry-level jobs may lead to higher, not lower, unemployment. And, even if unemployment comes down, workers may actually be worse off, going through many spells of unemployment and low productivity entry-level jobs, before obtaining a regular job. ${ }^{2}$

Our purpose in this paper is to explore this argument, both theoretically and empirically. Our interest is broader than just the effects of fixed duration contracts in France. We see our paper as shedding some light on two larger issues. First, the effect of labor market institutions on the nature of the labor market - a popular but often fuzzy theme. Second, the pitfalls of partial labor market reforms.

Our paper is organized as follows: We develop a formal model in Section 1. We solve it analytically in Section 2. We further explore its properties by use of simulations in Section 3. The model makes clear that partial reform can indeed be perverse, increasing unemployment as well as decreasing welfare. We then turn to the empirical evidence, looking at the effects of the introduction of fixed duration contracts in France since the early 1980s.

\footnotetext{
${ }^{2}$ The French have a word for such a succession of unemployment spells and lowproductivity jobs: They call this "precarité". There does not seem to be an equivalent English expression - although there is an adjective, "precarious". "Insecurity" may come close.
} 
Section 4 shows the basic evolutions. Section 5 focuses on labor market evolutions for 20-24 year olds, the group most affected by the increase in fixed-duration contracts. The section looks at the evolution of transitions between entry-level jobs, regular jobs, and unemployment, and also looks at wages by contract type. The reforms appear to have substantially increased turnover, without a substantial reduction in unemployment duration. If anything, their effect on welfare of young workers appears to have been negative. Section 6 concludes. ${ }^{3}$

\section{A simple model}

In formalizing the labor market, we think of it as a market in which matchidiosyncratic productivity shocks lead to separations and new hires. In that context, we think of employment protection as layoff costs, affecting both the layoff decision and the nature of bargaining between workers and firms.

In this section, we describe the model, derive the Bellman equations, and characterize the equilibrium conditions.

\subsection{Assumptions}

The economy has a labor force of mass 1 . There is a constant flow of entrants equal to $s$, and each individual retires with instantaneous probability (Poisson parameter) $s$, so the flow of retirements is equal to the flow of entrants.

\footnotetext{
${ }^{3}$ Throughout, our focus is on the economic effects of the introduction of fixed duration contracts, not on their political economy implications. These political economy issues, which are highly relevant to the design of employment protection reforms, have been studied by Gilles Saint-Paul in a series of contributions, in particular Saint-Paul [1996] and Saint-Paul [2000].
} 
Firms are risk neutral value maximizers. They can create a position at cost $k$, and then operate it forever. ${ }^{4}$ They can always fill the position instantaneously, by hiring a worker from the pool of unemployed. In other words, the matching technology has "workers waiting at the gate". 5 The number of positions in the economy is determined by free entry, and thus by the condition that there is zero net profit. The interest rate is equal to $r$.

New matches all start with productivity equal to $y_{0}$. Productivity then changes with instantaneous probability $\lambda$. The new level of productivity $y$ is drawn from a distribution with cumulative distribution function $F(y)$ and expected value Ey. $y$ is then constant until the worker retires.

Nothing in the algebra depends on it, but it is natural to think of $y_{0}$ as smaller than Ey. This captures the idea that workers start in low productivity, "entry-level" jobs, and, if they are not laid off, move on to higher productivity, "regular" jobs. The assumption that, after the first draw, productivity is constant until the worker retires, is also inessential but captures in the simplest way the notion that regular jobs are likely to last much longer than entry-level jobs.

When productivity changes from $y_{0}$ to $y$, the firm can decide either to lay off the worker - and hire a new worker in an entry-level job with productivity $y_{0}$ - or keep him in a regular job, with productivity $y$ (until the worker retires, at which point the firm hires a new worker with productivity $\left.y_{0} \cdot\right)$

At the center of our model and crucial to the firm's decisions are stateimposed firing costs. We take them to be pure waste (think administrative

\footnotetext{
${ }^{4}$ Allowing Poisson stochastic depreciation for positions would introduce an additional parameter, but not change anything of substance.

${ }^{5}$ The effects of matching frictions on the equilibrium are well understood. Leaving them out makes it easier to focus on the distortions implied by employment protection.
} 
and legal costs) rather than transfers. ${ }^{6}$ The firing cost associated with an entry-level job (i.e. up to and including the time at which the productivity level changes from $y_{0}$ to $y$ ) is $c_{0}$. The firing cost associated with a regular job (i.e. starting just after the change in productivity from $y_{0}$ to $y$ ) is $c$. Separations due to retirement are not subject to firing costs.

We can look at the same labor market from the point of view of the workers. Workers are risk neutral, with discount rate equal to $r$, and they retire with instantaneous probability $s$. By normalization, the flow utility of being unemployed is equal to 0 . New workers enter the labor market unemployed. They look for an entry-level job, which they find with probability $x$, where $x=h / u$, with $h$ being the flow of hires, and $u$ being the unemployment rate. Their entry-level job comes to an end with instantaneous probability $\lambda$, at which time they are either laid off, or retained in a regular job. If they are laid off, they become unemployed, and look for another entry-level job. The model therefore generates a work life-cycle, in which young workers typically go through a succession of unemployment spells and entry-level jobs until they obtain a regular job, which they keep until they retire.

The flow into unemployment is composed of new entrants and of those workers who are laid off at the end of their entry-level job. The flow out of unemployment is equal to the number of workers hired in new entry-level jobs. All regular jobs are filled from within, and all regular jobs end with retirement.

The only element of the model left to specify is wage determination.

\footnotetext{
${ }^{6}$ What we need is that at least some component of firing costs be waste. The implications of thinking about firing costs as waste or as transfers, and the scope for bonding to cancel the effects of the transfer component, are well understood. See for example Lazear [1990]. We think that there is enough evidence of waste and limited bonding to warrant our assumption.
} 
We assume that wages, both in entry-level and in regular jobs, are set by symmetric Nash bargaining, with continuous renegotiation. All entry-level jobs have the same level of productivity $y_{0}$ and thus pay the same wage $w_{0}$. Regular jobs have different levels of productivity; the wage in a regular job with productivity $y$ is denoted $w(y)$.

Given the way we have set up the model, distortions in this economy come only from the presence of the two firing costs, $c$ and $c_{0}$. Our focus in this paper will be on the effects of a decrease in $c_{0}$ given $c$, i.e. of a decrease in the firing costs associated with entry-level jobs, keeping unchanged the firing costs associated with regular jobs. ${ }^{7}$

\subsection{Bellman equations}

Consider first the Bellman equations characterizing the firm. Let $V_{0}$ be the expected present value of profits from a position currently filled as an entry-level job (the value of an entry-level job for short), a job with current productivity equal to $y_{0}$. Let $V(y)$ be the value of a regular job with productivity equal to $y$. Let $y^{*}$ be the threshold level of productivity above which the firm keeps a worker, and below which it lays him off.

$V_{0}$ is given by:

$$
r V_{0}=\left(y_{0}-w_{0}\right)-c_{0} \lambda F\left(y^{*}\right)+\lambda \int_{y^{*}}^{\infty}\left(V(y)-V_{0}\right) d F(y)
$$

The first term on the right gives flow profit. The second gives the firing cost associated with terminating the entry-level job, times the probability

\footnotetext{
${ }^{7}$ Note that our assumption that regular jobs are not subject to productivity shocks implies that the only role of $c$, the firing cost associated with regular jobs, is to affect wage bargaining in regular jobs, not layoffs from regular jobs. Allowing for productivity shocks to regular jobs would complicate the algebra, generate a richer structure of flows, but not change anything of substance.
} 
that the worker is laid off-itself equal to the probability of a productivity change, times the probability that $y$ is less than the threshold value $y^{*}$. The third term reflects the expected change in the value of the job if the worker is kept in a regular job. (Note the absence of a term reflecting the probability that the worker retires. If the worker retires while in an entry-level job, the firm can replace him instantaneously at no cost by a worker with the same productivity, so this term is equal to $s\left(V_{0}-V_{0}\right)=0$.) The sum of these three terms must be equal to the annuity value of an entry level job, $r V_{0}$

$V(y)$ is given in turn by:

$$
r V(y)=(y-w(y))+s\left(V_{0}-V(y)\right)
$$

The first term on the right gives flow profit if productivity is equal to $y$. The second term reflects the change in value if the worker retires and the firm must hire a new worker at productivity level $y_{0}$. The sum of the two must be equal to the annuity value of a regular job, $r V(y)$.

Turn to the Bellman equations for a worker. Let $V_{0}^{e}$ denote the expected present value of utility for a worker currently in an entry-level job (the value of being in an entry-level job for short), $V^{u}$ the present value of utility for a worker currently unemployed (the value of being unemployed for short), and $V^{e}(w(y))$ is the value of being employed in a regular job with productivity $y$. Note that $V^{u}$ is also the expected lifetime utility of an entrant in the labor market; for this reason, it is a natural measure of welfare in this model.

$V_{0}^{e}$ is given by:

$$
r V_{0}^{e}=w_{0}+\lambda F\left(y^{*}\right)\left(V^{u}-V_{0}^{e}\right)-s V_{0}^{e}+\lambda \int_{y^{*}}^{\infty}\left(V^{e}(w(y))-V_{0}^{e}\right) d F(y)
$$

The first term on the right is the wage for an entry-level job. The second is the probability that the job ends, times the change in value from going 
from employment to unemployment. The third reflects the loss in value from retirement. The fourth reflects the expected change in value if the worker is retained in a regular job. The sum of these terms is equal to the annuity value of the value of being in an entry-level job.

$$
V^{e}(w(y)) \text { is given by: }
$$

$$
r V^{e}(w(y))=w(y)-s V^{e}(w(y))
$$

The worker receives the wage associated with productivity level $y$, until he retires, in which case he loses the value of being employed in a regular job. The sum of these terms is equal to the annuity value of being employed in a regular job.

Finally, $V^{u}$ is given by:

$$
r V^{u}=x\left(V_{0}^{e}-V^{u}\right)-s V^{u}
$$

The first term is equal to the probability of being hired in an entry-level job, the second the probability of retiring while unemployed, times the loss in value from retirement. The sum of these terms must be equal to the annuity value of being unemployed.

\subsection{Equilibrium conditions}

The model imposes four equilibrium conditions. The first is the free entry condition, that the value of a new position be equal to the cost of creating it:

$$
V_{0}=k
$$

The second is that, at the threshold level of productivity, the firm be indifferent between keeping the worker, or laying him off, paying the firing cost, and hiring a new worker: 


$$
V\left(y^{*}\right)=V_{0}-c_{0}
$$

The third is the Nash bargaining condition for entry-level jobs. A worker who loses an entry-level job loses $V_{0}^{e}-V^{u}$. A firm which lays off a worker in an entry-level job loses $V_{0}-V_{0}+c_{0}=c_{0}$. This implies:

$$
V_{0}^{e}-V^{u}=c_{0}
$$

The fourth is the Nash bargaining condition for regular jobs. A worker who loses a regular job loses $V^{e}(w(y))-V^{u}$. A firm which lays off a worker in a regular job loses $V(y)-V_{0}+c$. The Nash condition therefore takes the form:

$$
V^{e}(w(y))-V^{u}=V(y)-V_{0}+c
$$

We now turn to a characterization of the equilibrium.

\section{The equilibrium}

The equilibrium is easiest to characterize by focusing on two variables, $V^{u}$, the value of being unemployed, and $y^{*}$, the threshold level of productivity below which workers are laid-off.

One can then think of the equilibrium in terms of two relations. The first, which we shall call the "layoff relation", gives threshold productivity $y^{*}$ as a function of labor market conditions, summarized by $V^{u}$, and of the two firing costs $c$ and $c_{0}$. The second, which we shall call the "hiring relation" gives $V^{u}$, the value of being unemployed as a function of $y^{*}$ and the two firing costs $c$ and $c_{0}$. Together the two relations determine $V^{u}$ and $y^{*}$. Once this is done, all other variables can easily be derived, and so can the effects of changes in firing costs. 


\subsection{The layoff relation}

The condition determining the choice of the threshold productivity value $y^{*}$ by the firm is given by (1.2). Using equation (1.4), it can be rewritten as:

$$
\left(V\left(y^{*}\right)-V_{0}+c_{0}\right)+\left(V^{e}\left(w\left(y^{*}\right)\right)-V^{u}\right)=c-c_{0}
$$

Note that the right side gives the total surplus (i.e the surplus to the firm and the surplus to the worker from staying together rather than separating) from a match with productivity $y^{*}$. Were the choice of the threshold productivity level privately efficient, the threshold productivity level would be chosen so that the total surplus was equal to zero. As (2.1) shows, unless $c-c_{0}$ is equal to zero, this is not the case here. If $c$ exceeds $c_{0}$, so $c-c_{0}$

is positive, some workers will be laid-off despite the fact that keeping them would yield a positive total surplus. The source of the distortion is clear: If $c$ is higher than $c_{0}$, the worker, if kept in a regular job, will be in a stronger bargaining position and thus be able to extract a higher wage. Anticipating this, the firm will only keep jobs where the surplus is sufficiently large to offset this increase in the worker's bargaining power.

Using the Bellman equations to derive $V\left(y^{*}\right)+V\left(w\left(y^{*}\right)\right)$, together with the free entry condition $V_{0}=k$, gives the first relation between $y^{*}$ and $V^{u}$ :

$$
\frac{y^{*}+s k}{r+s}-V^{u}-k=-c_{0}+\left(c-c_{0}\right)
$$

We shall refer to this relation as the "layoff relation" between $y *$ and $V^{u}$. The left side gives the total gross surplus (i.e. ignoring firing costs) of a match of productivity $y^{*}$. The first term is the expected value of output. The next two terms subtract the outside options of workers and firms.

The two terms on the right side show the two roles of $c_{0}$ in determining $y^{*}$. If the layoff decision were privately efficient, only the first term would be present: The firm would choose $y^{*}$ so that the net surplus on a job with 
productivity $y^{*}$ was equal to zero. The second term reflects the private distortion due to bargaining. It implies that, if $c$ is higher than $c_{0}$, then $y^{*}$ will be (privately) inefficiently high.

We can now look at the effects of $V_{u}, c$ and $c_{0}$ on $y^{*}$. The derivatives are as follows:

$$
\frac{d y^{*}}{d V^{u}}=(r+s)
$$

The higher the value of being unemployed $V^{u}$, the higher must be the productivity of the marginal match.

$$
\frac{d y^{*}}{d c_{0}}=-2(r+s)
$$

The lower the firing cost for entry-level jobs, $c_{0}$, the higher the threshold (and also the larger the deviation of the threshold $y^{*}$ from its privately efficient level, thus the larger the overdestruction).

\subsection{The hiring relation}

The derivation of the second relation between $V^{u}$ and $y^{*}$ starts with the Nash bargaining condition for entry-level jobs, equation (1.3). Adding and subtracting $V_{0}$, this equation can be rewritten as:

$$
\left(V_{0}^{e}+V_{0}\right)-\left(V_{0}+V^{u}\right)=c_{0}
$$

Note that the right side is equal to the surplus from a new match. The first term in parentheses is the expected value of output from the match. The second term in parentheses is equal to the sum of the outside option of the worker and the firm. Note that, again, this condition is not (privately) efficient. Firms should hire workers until the surplus from a match was equal to zero. This is not the case here: The surplus is only driven down to $c_{0}$, not to zero. Just as before, this distortion reflects the increased bargaining 
power of workers coming from renegotiation in the presence of firing costs.

Using the Bellman equations to replace $V_{0}^{e}+V_{0}$, together with the free entry condition $V_{0}=k$ gives:

$$
\begin{array}{r}
y_{0}+s k+\lambda \int_{y^{*}}^{\infty} \frac{y+s k}{r+s} d F(y)-\left(r+s+\lambda\left(1-F\left(y^{*}\right)\right)\right)\left(V^{u}+k\right)= \\
\lambda F\left(y^{*}\right) c_{0}+(r+s+\lambda) c_{0}
\end{array}
$$

This gives the second relation between $V^{u}, y^{*}$, and $c_{0}(c$ does not appear here). In effect, it gives the value of being unemployed such that the wages set in bargaining, and by implication, the present value of profits associated with a new position just cover the cost of creating that position and hiring the worker. We shall call it the "hiring relation".

Up to a discount factor $(r+s+\lambda)$, the left side gives the total gross surplus from creating a new job and hiring a worker (gross of the firing cost which may have to be paid if the productivity shock turns out to be lower than the threshold).

Turning to the right side, note that there are two terms in $c_{0}$. Were hiring privately efficient, then only the first term on the right side would be present. Hiring would take place until the total gross surplus was equal to the expected firing cost (the probability that firing takes place times the firing cost). The second term reflects the distortion coming from the effect of $c_{0}$ on the bargaining position of workers.

We can now look at the effects of $y^{*}$ and $c_{0}$ on $V^{u}$. The effect of $y^{*}$ on $V^{u}$ is given by:

$$
\left(r+s+\lambda\left(1-F\left(y^{*}\right)\right)\right) \frac{d V^{u}}{d y^{*}}=\lambda f\left(y^{*}\right)\left(V^{u}+k-c_{0}-\frac{y^{*}+s k}{r+s}\right)
$$

The sign of the derivative appears ambiguous: An increase in $y^{*}$ leads 
both to a higher expected output in continuing jobs, but also to a higher probability that jobs are terminated. But, in fact, we can say more, and this will be important later on:

At the equilibrium (i.e. at the intersection with the first relation, (2.2)), the derivative is given by:

$$
\left(r+s+\lambda\left(1-F\left(y^{*}\right)\right)\right) \frac{d V^{u}}{d y^{*}}=-\lambda f\left(y^{*}\right)\left(c-c_{0}\right) \leq 0
$$

If both $\left(c-c_{0}\right)$ and the density function $f\left(y^{*}\right)$ are different from zero, then an increase in $y^{*}$ leads to a decrease in $V^{u}$. If either $c=c_{0}$ or $f\left(y^{*}\right)=0$, then $V^{u}$ is independent of $y^{*}$. The intuition is as follows: As we saw earlier, if $c=c_{0}$, the layoff decision is privately efficient, so a small change in $y^{*}$ has no effect on the surplus and thus no effect on the feasible $V_{u}$. If $c>c_{0}$ however, the marginal regular job generates a positive surplus, so an increase in $y^{*}$, if it leads to an increase in the layoff rate (i.e. if $f\left(y^{*}\right)>0$ ) leads to a smaller total surplus, requiring a decrease in the feasible $V_{u}$.

Now consider the effect of $c_{0}$ on $V_{u}$ (given $y^{*}$ ). From (2.3):

$$
\left(r+s+\lambda\left(1-F\left(y^{*}\right)\right)\right) \frac{d V^{u}}{d c_{0}}=-(r+s+\lambda)-\lambda F\left(y^{*}\right)<0
$$

An increase in $c_{0}$ decreases the feasible value of being unemployed, $V^{u}$. There are two separate effects at work here. The first, captured by $-\lambda F\left(y^{*}\right)$, is a direct cost effect: An increase in $c_{0}$ increases firing costs actually paid by firms, and therefore increases waste, leading to a decrease in the feasible value of $V^{u}$. The second, captured by $(r+s+\lambda)$, reflects the effects of firing costs through bargaining. Both effects require new matches to generate a larger surplus. In equilibrium, this is achieved through a lower value of $V^{u}$. $^{8}$

\footnotetext{
${ }^{8}$ This is a familiar result from bargaining or efficiency wage models, (for example Shapiro and Stiglitz [1984], or more recently Caballero and Hammour [1996]), that, in equilibrium, unemployment plays the role of a market "discipline device". In these mod-
} 


\subsection{The equilibrium}

The two relations we have just derived are drawn in Figure 1. The first relation, (2.2), the "layoff relation", is upward sloping: The higher $V^{u}$, the higher the threshold $y^{*}$. The second relation, the "hiring relation", is either flat or downward sloping (it is drawn as downward sloping here), at least around the equilibrium: $V^{u}$ is either invariant to, or a decreasing function of, $y^{*}$. Together the two relations determine the threshold productivity level and the value of being unemployed. The equilibrium is given by point $A$.

The effects of a partial reform of employment protection, i.e. the effects of a decrease in $c_{0}$ on $y^{*}$ and on $V^{u}$, keeping $c$ constant, are then easy to derive. The layoff relation shifts to the right: For given $V^{u}$, the lower value of $c_{0}$ makes it more attractive to layoff entry-level workers, and thus increases $y^{*}$. The hiring relation condition shifts up: For given $y^{*}$, lower $c_{0}$ leads to a higher value of $V^{u}$, both because of the reduction in costs, and because of the decrease in the bargaining power of entry-level workers.

The new equilibrium is given by point $B$. It is clear that, while $y^{*}$ unambiguously increases, the effect on $V^{u}$ is ambiguous. This is because there are two distortions at work, and they work in opposite directions.

- On the one hand, the decrease in $c_{0}$ leads to an increase in $\left(c-c_{0}\right)$ and thus to an increase in the distortion affecting the layoff relation (a distortion which depends on the bargaining power in regular jobs relative to entry-level jobs). This tends to decrease $V^{u}$.

- On the other hand, the decrease in $c_{0}$ leads to a decrease in the distortion affecting the hiring relation (a distortion which depends on the bargaining power of workers in entry-level jobs). This tends to increase $V^{u}$.

els, the zero profit condition ties down the wage. Any factor which increases the wage given reservation utility requires, in equilibrium, a decrease in reservation utility. 
FIGURE 1.

Equilibrium value of being unemployed and threshold productivity, and the effects of a decrease in $\mathrm{c} 0$

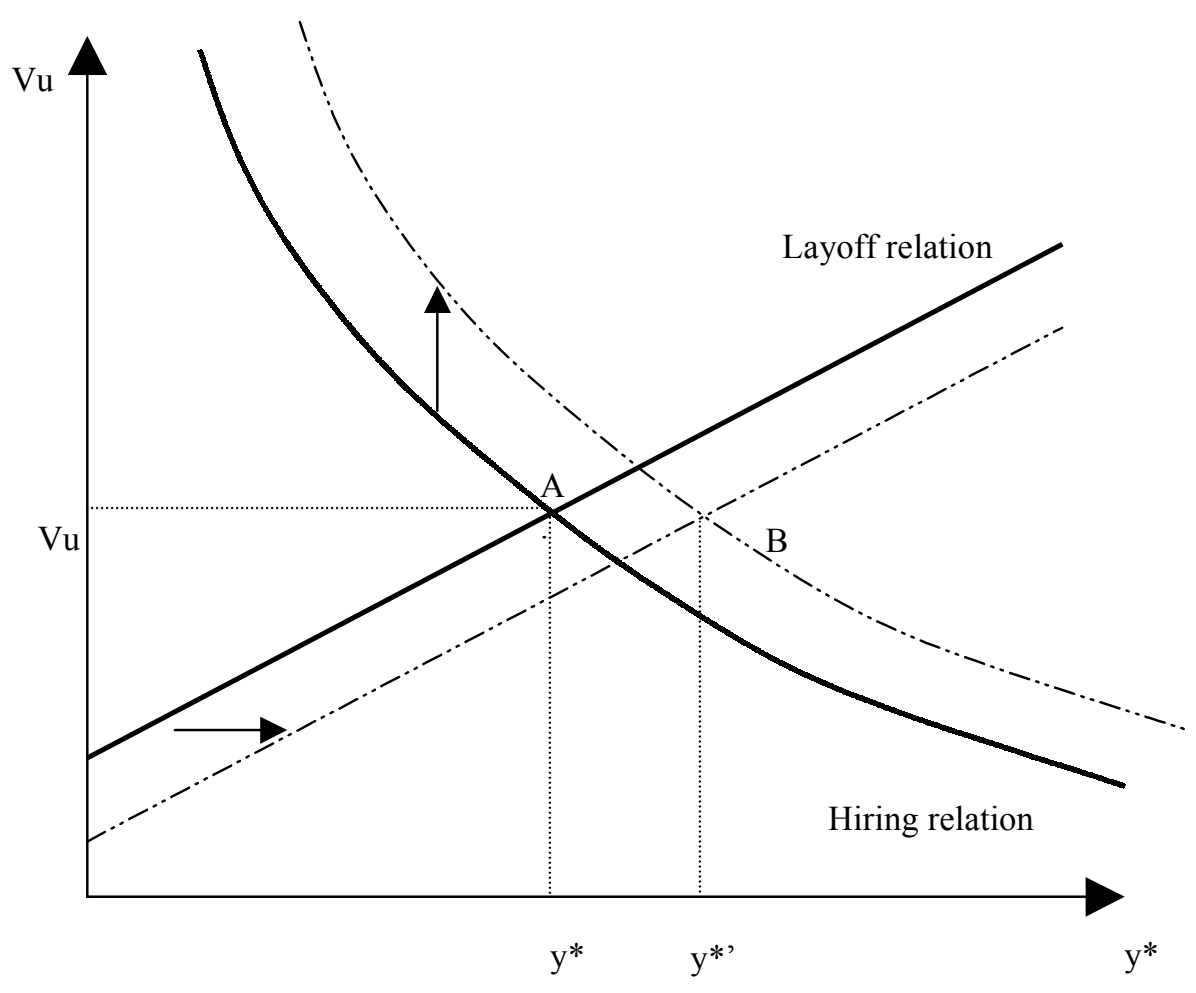


To see the two effects more clearly, suppose first that $\left(c-c_{0}\right)$ is equal to zero to start. In this case the first distortion is absent and, as we saw, small changes in $y^{*}$ have no effect on $V^{u}$ in the hiring relation. Thus, the only effect of a decrease in $c_{0}$ on $V^{u}$ is through its direct effect in the hiring relation relation: By both decreasing waste and decreasing the bargaining power of entry-level workers, the decrease in $c_{0}$ leads to an unambiguous increase in $V^{u}$.

This case is represented in Figure 2. We know from above that, if $(c-$ $\left.c_{0}\right)=0$, the hiring relation is flat at the equilibrium. The decrease in $c_{0}$ shifts the hiring relation condition up: Lower costs and lower bargaining power by entry-level workers lead to a higher equilibrium value of $V^{u}$. The decrease in $c_{0}$ shifts the layoff relation to the right: For given $V^{u}$, a decrease in $c_{0}$ makes layoffs more attractive, leading to an increase in $y^{*}$. The equilibrium moves from $\mathrm{A}$ to $\mathrm{B}$, with higher $V^{u}$, and a higher threshold, $y^{*}$.

When $\left(c-c_{0}\right)$ is positive instead, the effect of the decrease in $c_{0}$ on the first distortion becomes relevant. The decrease in $\left(c-c_{0}\right)$ leads to an increase in the first distortion, and thus, other things equal, to a decrease in $V^{u}$. The strength of this effect is proportional to $\left(c-c_{0}\right) f\left(y^{*}\right)$ and is thus increasing in the density evaluated at the equilibrium-in the number of entry-level jobs which are (inefficiently) terminated as a result of the increase in $y^{*}$. If either $\left(c-c_{0}\right)$ or $f\left(y^{*}\right)$ are sufficiently large, this adverse effect can dominate. Figure 3 is drawn on the assumption that $f(y)$ is very large around $y=y^{*}$, so the hiring relation is (nearly) vertical. In this case, a decrease in $c_{0}$ does not shift the hiring relation. But, as before, it shifts the layoff relation to the right: For given $V^{u}$, a decrease in $c_{0}$ makes layoffs more attractive, leading to an increase in $y^{*}$. The equilibrium moves from A to $\mathrm{B}$, with lower value $V^{u^{\prime}}$, and an unchanged threshold, $y^{*}$.

To summarize, we have a first answer to our initial question. If $\left(c-c_{0}\right)$ or/and $f\left(y^{*}\right)$ are sufficiently large, a partial reform may indeed lead to an 
FIGURE 2.

The effects of a decrease in $\mathrm{c} 0$ starting from $\mathrm{c}-\mathrm{c} 0=0$

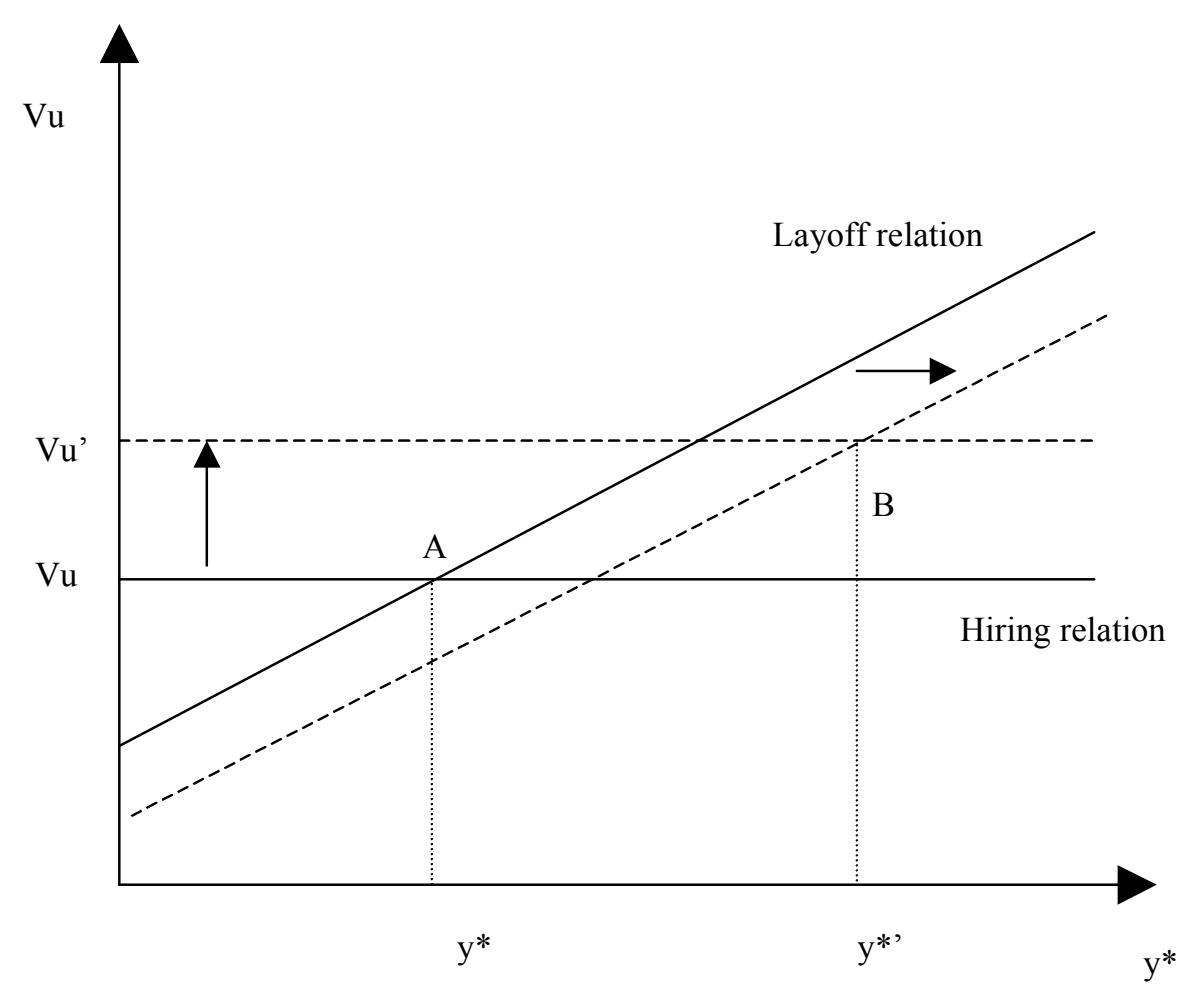


FIGURE 3.

The effects of a decrease in $\mathrm{c} 0$ when $(\mathrm{c}-\mathrm{c} 0)$ is positive and $\mathrm{f}($.$) is very large$

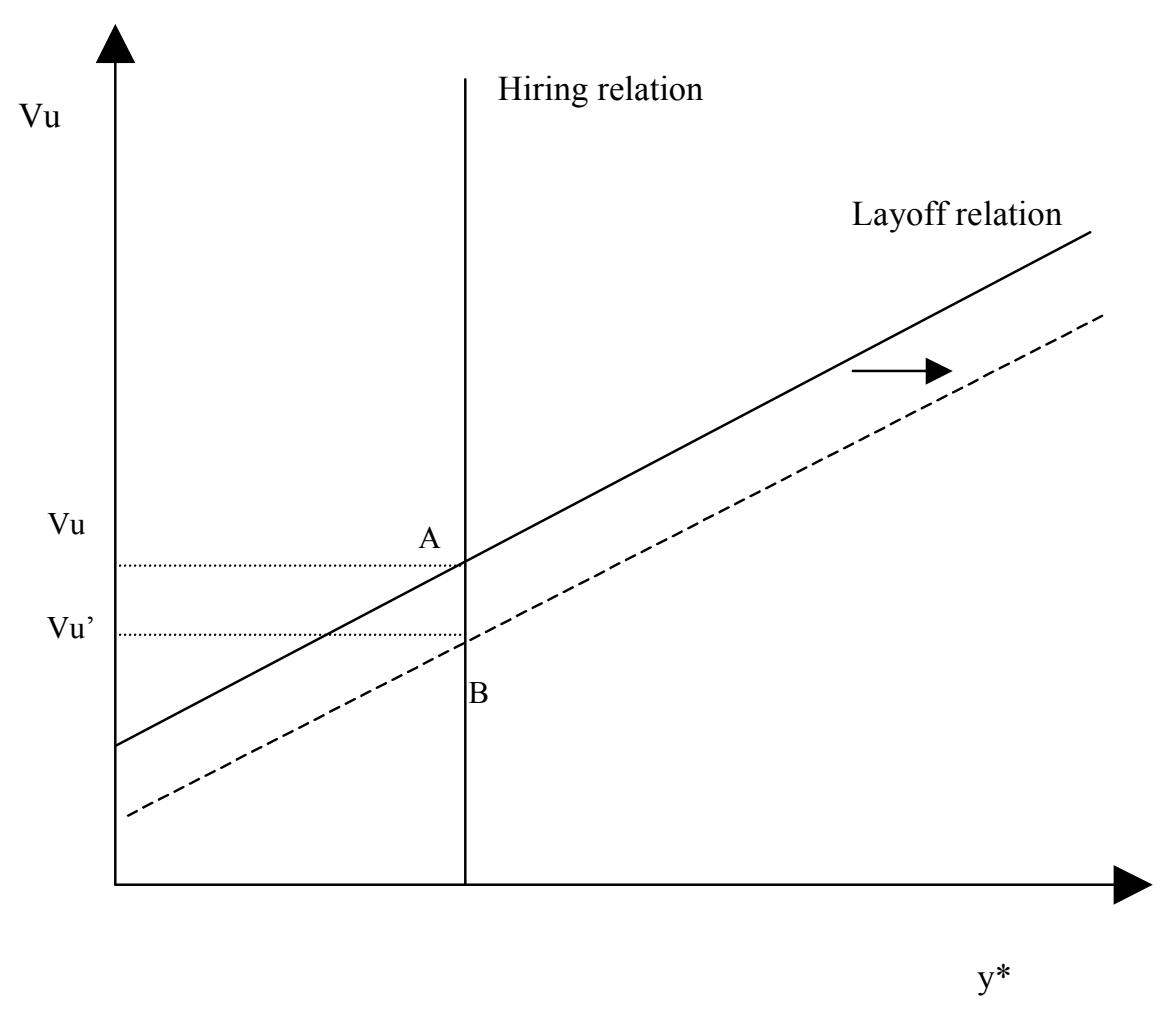


increase in excess turnover, and, by implication, to a decrease in the value of being unemployed..$^{9}$

\subsection{Other wage setting assumptions}

We have assumed symmetric Nash bargaining. It is easy to extend the analysis to allow for differential bargaining power, both between firms and workers, and between workers in entry-level and in regular jobs. The results of this extension are straightforward. The higher the bargaining power of workers in regular jobs relative to that of workers in entry-level jobs, the stronger the effect of a decrease in $c_{0}$ on the first distortion, the more likely it is that partial reform leads to a decrease rather than an increase in welfare.

We have also examined the effects of a minimum wage constraint. As we shall discuss and explain below when presenting simulations, under the Nash bargaining assumptions, decreases in $V^{u}$ are associated with an increase in $w_{0}$. Thus, a constraint which prevents the wage from decreasing, such as a minimum wage constraint, will not be binding, and will not rule out perverse effects of partial reform on welfare (A constraint which prevents the wage from increasing will increase welfare; but this does not seem to be the right representation of a minimum wage constraint.)

\subsection{Other implications}

Given the equilibrium values of $y^{*}$ and $V^{u}$, it is straightforward to derive the other variables of the model. For example:

- The layoff rate is given by $\lambda F\left(y^{*}\right)$, so a decrease in $c_{0}$, which, as we have seen, unambiguously increases $y^{*}$, unambiguously increases the

\footnotetext{
${ }^{9}$ Note that, for values of the parameters that give rise to this effect, the value of $c_{0}$ that maximizes $V^{u}$ will be less than $c$ but positive. Thus, this can be seen as an argument for partial "partial reform" (i.e. some decrease in $c_{0}$ from $c$, but not all the way to zero)...
} 
layoff rate.

- Using the condition that $\left(V_{0}^{e}-V^{u}\right)=c_{0}$, the hiring rate from unemployment $x$ is given by $x=(r+s) V^{u} / c_{0}$. Thus, if reform is welfare improving - if $V^{u}$ increases when $c_{0}$ decreases - we know that $x$ increases, equivalently, unemployment duration decreases. But the effect is ambiguous in general.

- The unemployment rate is given by $u\left(x+s-\left(\lambda F\left(y^{*}\right) x\right) /(\lambda+s)\right)=$ $s$. Even if unemployment duration decreases ( $x$ increases), higher turnover $\left(F\left(y^{*}\right)\right.$ increases) implies an ambiguous effect on the unemployment rate.

- From the Nash bargaining conditions, the values of being employed in an entry-level job, of being employed in a regular job with productivity equal to the threshold, and of being unemployed, are related by $V_{0}^{e}-$ $V^{u}=c_{0}$ and $V^{e}\left(w\left(y^{*}\right)\right)-V_{0}^{e}=c-2 c_{0}$. Thus, a decrease in $c_{0}$ makes entry-level jobs more like unemployment (decreasing $c_{0}$ ), and entrylevel jobs less like regular jobs (increasing $c-2 c_{0}$ ). In this sense, a reduction in $c_{0}$ leads to increased dualism in the labor market.

To fully characterize the effects of the decrease in $c_{0}$ on the different dimensions of our economy, it is more convenient to turn to simulations. This is what we do in the next section.

\section{Simulations}

Our goal in this section is to show the effects of partial reform both on the work life-cycle of an individual worker, as well as on macro aggregates, from unemployment to GDP.

We think of the unit time period as one month, and choose the parameters as follows: 
- We normalize the level of output on an entry-level job, $y_{0}$ to be equal to 1 .

- We take $k$ to be equal to 24 , implying a ratio of capital to annual output on an entry-level job of 2 .

- We take the monthly real interest rate, $r$, to be equal to $1 \%$. Together with the two previous assumptions, this implies a share of labor in output on entry-level jobs, of $(1-.01 * 24)=76 \%$.

- We take the monthly probability of exogenous separation ("retirement") $s$, to be equal to $1.5 \%$.

- We take the monthly probability of a productivity change on an entrylevel job, $\lambda$ to be equal to $10 \%$. This implies an expected duration of an entry-level job of about a year.

- We take the distribution of productivity on regular jobs to be uniform, distributed on $[m-1 / 2 f, m+1 / 2 f]$, thus with mean $m$, and density $f$. The use of a uniform distribution makes particularly transparent the influence of the density $f$ on the effects of partial reform.

- To capture the notion that regular jobs are more productive, we set the mean $m$ equal to 1.4. (Because jobs below the threshold are terminated, the mean of the observed distribution will be higher.)

- Because our theoretical analysis in the previous section showed that the density function plays a crucial role in determining the outcome, we look at the effects of reform for different values of $f$. The graphs below show the results of reform for values of $f$ varying from 1 to 6 .

- We choose the firing cost on regular jobs, $c$, equal to 24 - which, in most simulations, represent about a year and a half of average output. 
We shall discuss the legal and empirical evidence for France in the next section; we believe this to be a reasonable estimate.

Our simulations then focus on the effects of a decrease in $c_{0}$. If $c_{0}$ is either too large or too small, the equilibrium may be at a corner, i.e. at a point where $y^{*}$ lies outside the support of the productivity distribution for regular jobs. In those cases, changes in $c_{0}$ have no effect on the layoff rate; their effect takes place only through bargaining. While these corner equilibria are interesting, we limit the presentation of results to the range where there is an interior solution, so changes in $y^{*}$ affect the layoff rate. The results below are presented for the range where $c_{0}$ decreases from 6 to 2 months of output. The results are presented in Figures $4 \mathrm{a}, 4 \mathrm{~b}$, and 5 .

Figures $4 \mathrm{a}$ and $4 \mathrm{~b}$ show the effects of partial reform on different aspects of a worker's individual experience. Figure $4 \mathrm{a}$ plots $V^{u}$, the value of being unemployed, $F\left(y^{*}\right)$, the probability that the worker is laid-off at the end of an entry-level job, $x$ the monthly hiring rate from unemployment, and $T_{u}$, the expected time to a regular job starting from unemployment. Figure $4 \mathrm{~b}$ gives the behavior of wages in entry-level and regular jobs. These wages are given by $w(y)=a+0.5 y$ and $w_{0}=a_{0}+0.5 y_{0}$ respectively. Figure $4 \mathrm{~b}$ plots the two constant terms $a$ and $a_{0}$-which give the levels of wages for a given level of productivity.

For each $3 \mathrm{D}$ box, the firing cost $c_{0}$ is plotted on the $y$ axis, decreasing as one goes away from the origin. The density function $f$ is plotted on the $x$ axis, with the density decreasing as one goes away from the origin. The variable of interest is plotted on the vertical axis.

Start with $V^{u}$ in Figure 4a. For low density-low $f$-a decrease in $c_{0}$ increases $V^{u}$. But, for high density $f$, it decreases $V^{u}$. The basic intuition was given in the previous section. When $f$ is low, the adverse effects of reform on excess turnover are small, and workers are better off. When $f$ is high, the adverse effects of excess turnover dominate. 
Utility of an entrant

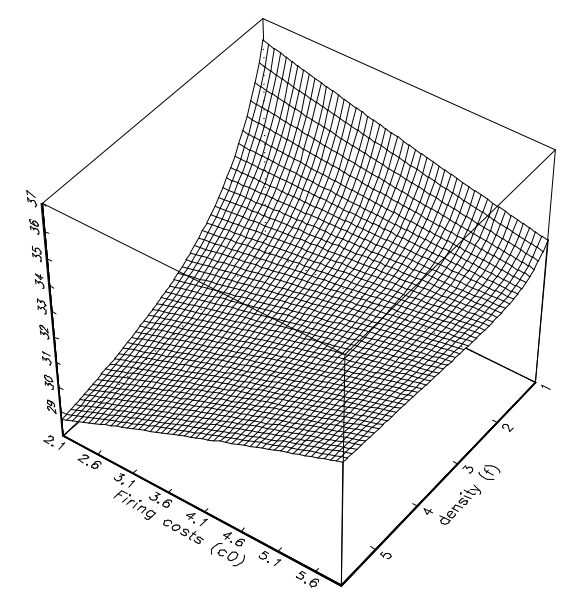

hiring rate

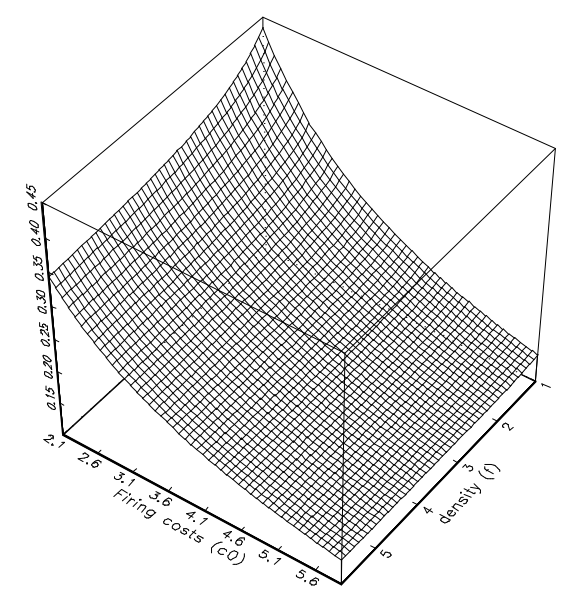

destruction rate $F(y *)$

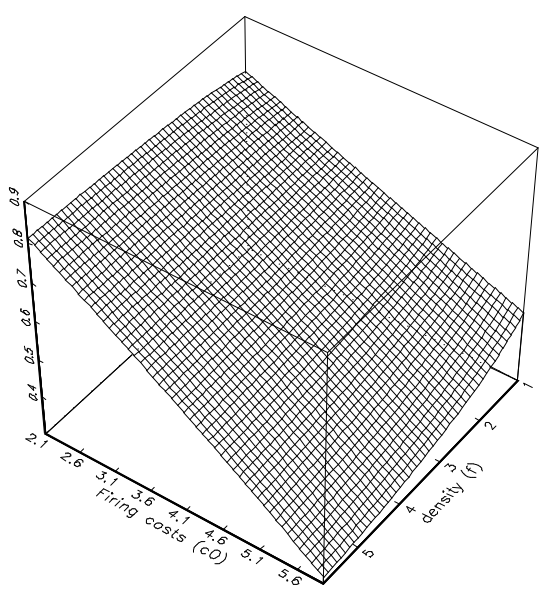

Tu: expected $U$ to $C D I$ trans. time

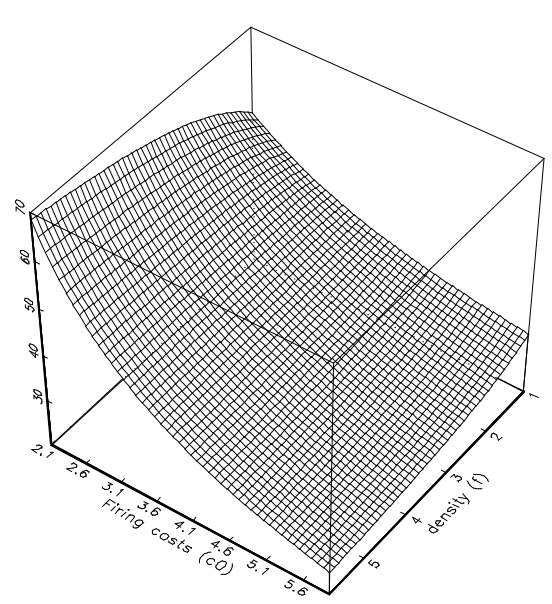


a in $w(y)=a+.5 y$

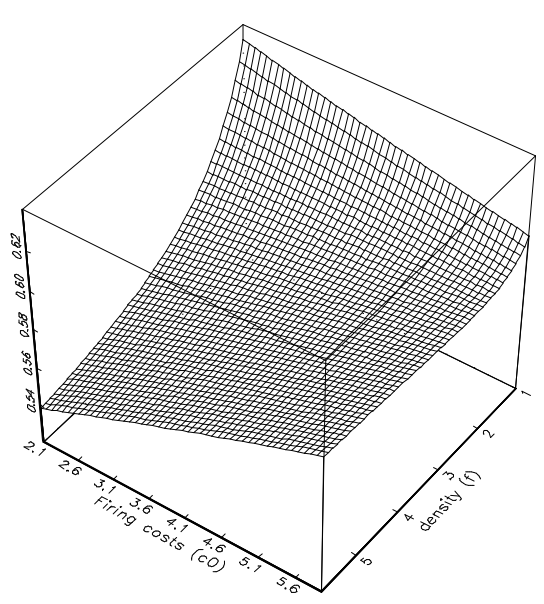

$a O$ in $w O=a O+.5 y O$

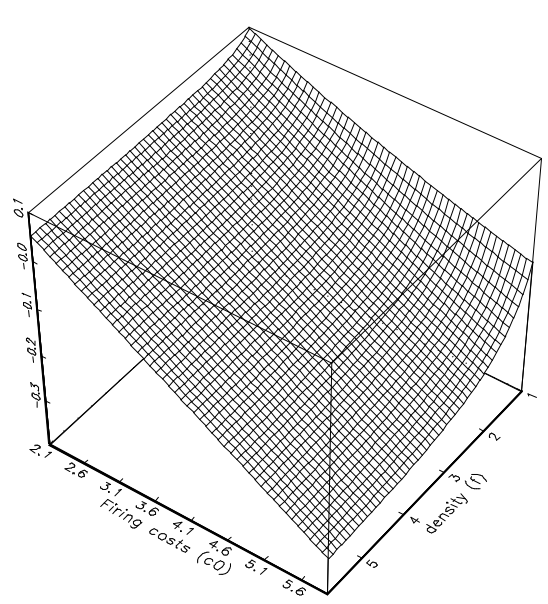


This intuition is confirmed by looking at $x$ and $F\left(y^{*}\right)$. While the effect of reform on $x$ is theoretically ambiguous, in our simulation reform always increases $x$, and thus decreases unemployment duration. It also increases the probability that an entry-level job will lead to a layoff (this effect is theoretically unambiguous). This second effect is stronger when density is high. For $f=6$, the probability increases from 0.3 to 0.8 ; for $f=1$, the probability increases from 0.45 to 0.75 .

The last box in Figure 4a shows that reform increases the average time it takes a new entrant to get a regular job. The effect is stronger when the density is high. For $f=6$, the expected time increases from two years to nearly six years.

Figure $4 \mathrm{~b}$ gives the behavior of wages for regular and entry-level jobs for a given level of productivity. The relative level of the two wages fits one's prior: Higher firing costs lead to higher bargaining power and thus a higher wage for regular jobs. But the effect of a decrease in $c_{0}$ is less intuitive at first:

- One might have guessed (i.e we had guessed) that the decrease in the relative bargaining power of entry-level workers would lead to a decrease in their wage relative to that of workers in regular jobs. This is not necessarily the case: In general equilibrium, the duration of unemployment changes, with differential effects on the two wages. Figure $4 \mathrm{~b}$ shows that the effect of reforms on the wage in regular jobs has the same sign as the effect on $V^{u}$ : Like $V^{u}$, the wage may go up or down; this reflects the tight link between reservation utility and the wage set in Nash bargaining for regular jobs. ${ }^{10}$

\footnotetext{
${ }^{10}$ It can be shown analytically that, in regions where reform is perverse- where $V^{u}$ goes down when $c_{0}$ goes down $-w_{0}$ decreases with $c_{0}$.
} 
- Perhaps even more surprisingly, the wage for entry level jobs goes up as $c_{0}$ goes down - the more so the higher the density. The way to understand this is in terms of bonding. The higher the density, the more a decrease in $c_{0}$ decreases the probability of being kept in a regular job. Thus, the lower the "bond" workers in entry-level jobs are willing to pay in the form of low wages, or equivalently, the higher the wage they require to take an entry-level job. ${ }^{11}$ There is another countervailing effect at work, lower bargaining power for workers in entry-level jobs, which leads to a decrease in the wage; but in our simulation, this effect is dominated by the first.

Figure 5 shows what happens to the macroeconomic aggregates. The first box repeats the graph for $V^{u}$ in Figure 4. We can think here of $V^{u}$ not as the value of being unemployed, but as average lifetime utility for a worker in the economy, thus as a measure of welfare.

The second box shows the effects of reform on the unemployment rate, and shows these effects to be ambiguous. For low density, the combined effects of lower duration and only slightly higher turnover lead to a decrease in unemployment. For high density, the effect is ambiguous. Unemployment first goes up as $c_{0}$ decreases, then goes down a bit. (This is a warning, if there was a need, that what happens to utility and to unemployment need not have the same sign. For high density, utility goes down strongly while unemployment goes up and then down.)

The third box plots the proportion of workers who are either unemployed or employed in entry-level jobs. The idea is to get at the idea of "precarite", the idea that the decrease in unemployment, if any, may come with a large increase in low productivity jobs. This proportion increases with reform, for

\footnotetext{
${ }^{11}$ From an interview of a worker on a fixed duration contract (CDD): "The only reason I took a CDD was to have a shot at a real job later on." Liberation [2000].
} 
Utility of an entrant

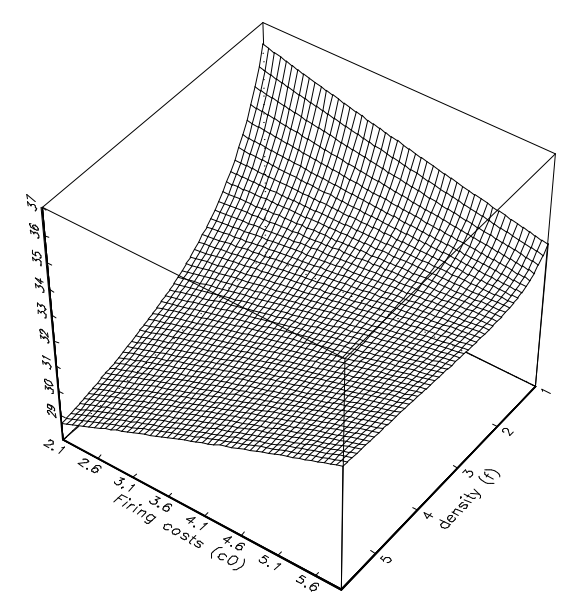

$C D D+U$

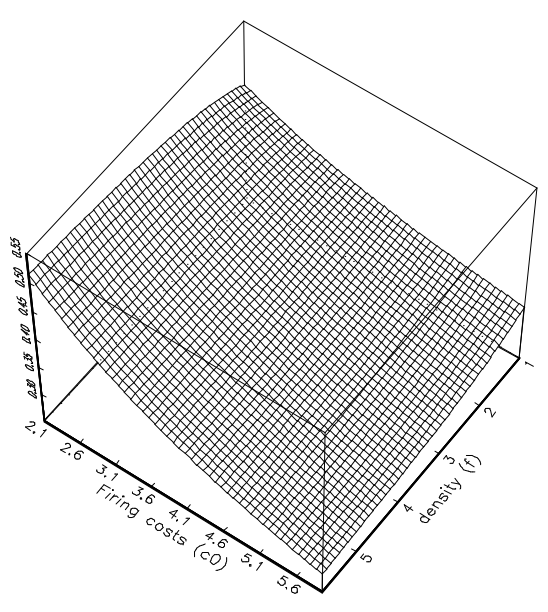

Unemployment rate

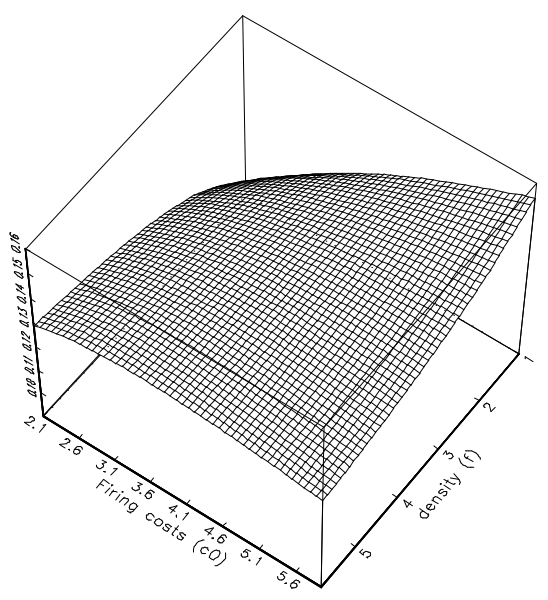

GDP

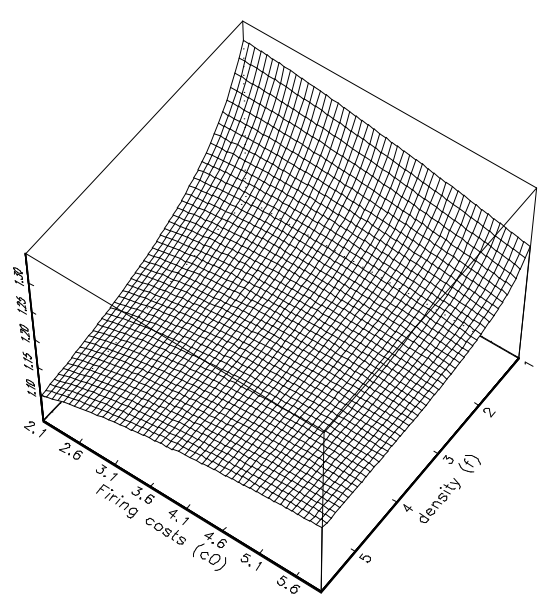


all values of $f$. Again, it is stronger when $f$ is high. In this sense, reform indeed increases precarite.

The last graph gives the value of GDP. For low density, the decrease in the unemployment rate, together with the limited increase in low productivity entry-level jobs, leads to an increase in output. For high density, the larger increase in the proportion of entry-level jobs, and the roughly constant unemployment rate, combine to lead to a decline in output - by nearly $5 \%$ under our parameter assumptions. Another warning is therefore in order here: What happens to output, to unemployment, and to utility, can all be quite different.

\section{The development of CDDs in France: Basic facts and evo- lutions}

In France, regular contracts, called "Contrats a duree indeterminée", or "CDI" for short, are subject to employment protection rules. Firms can layoff workers for one of two reasons: For "personal reasons", in which case they have to show that the worker cannot do the job he or she was hired for, or for "economic reasons", in which case, the firm must prove that it needs to reduce its employment. ${ }^{12}$

Barring serious negligence on the part of the worker, the firm must give both a notice period and a severance payment to the worker. The notice period is relatively short, 1 or 2 months depending on seniority. In the absence of a specific contract between unions and firms, the amount of severance pay set by law is also modest, typically $1 / 10$ of a month per year of work, plus $1 / 15$ of a month for years above 10 years. But firms perceive the costs to be much higher, because of the administrative and legal steps required to go through the process. The monetary equivalent of these costs (which are

\footnotetext{
${ }^{12}$ A useful source on French labor legislation is the Lamy [2000].
} 
indeed waste from the point of view of firms and workers) is hard to assess, but severance packages offered by firms in exchange for a quick resolution are typically much more generous than the legal minimum. ${ }^{13}$

Since the late 1970s, successive governments have tried to reduce these costs by introducing fixed-duration contracts, called "Contrats à durée determinée", or CDDs. These contracts still require a severance payment, but eliminate the need for a costly administrative and legal process. ${ }^{14}$

\subsection{The history and the current rules}

A brief history of CDDs goes as follows: CDDs were introduced in 1979. With the election of a socialist government in 1981 and the passage of a law in 1982, their scope was reduced: A list of 12 conditions was drawn, and only under those conditions could firms use fixed-duration contracts. In 1986, the 12 conditions were replaced by a general rule: CDDs should not be used to fill a permanent position in the firm. The current architecture dates for the most part to an agreement signed in March 1990.

Under this agreement, CDDs can be offered by firms for only one of four reasons: (1) The replacement of an employee on leave (2) Temporary increases in activity (3) Seasonal activities (4) Special contracts, aimed at facilitating employment for targeted groups, from the young to the long term unemployed. The list of special contracts has grown in the 1990s, as each government has tried to improve labor market outcomes for one group or another; some of these contracts require the firm to provide training, and many come with subsidies to firms.

CDDs are subject to a very short trial period, typically one month. They have a fixed duration, from 6 to 24 months depending on the specific

\footnotetext{
${ }^{13}$ For a comparison of France with other OECD countries, see OECD [1999].

${ }^{14}$ Poulain [1994] gives a detailed description of the rules governing CDDs.
} 
contract type. Mean duration is roughly one year. They typically cannot be renewed, and, in any case, cannot be renewed beyond 24 months. If the worker is kept, he or she must then be hired on a regular contract. If the worker is not kept, he or she receives a severance payment equal to $6 \%$ of the total salary received during the life of the contract (a law currently under consideration would raise this amount to $10 \%$ ).

Two other dimensions of these contracts are relevant here:

First, the law states that the wage paid to a worker under a CDD should be the same as the wage which would be paid to a worker doing the same job under a CDI. This is obviously difficult to verify and enforce, and, as we shall see, it appears not to be satisfied in practice.

Second, at the end of a CDD, workers qualify for unemployment benefits. Unemployment benefits start at either $40 \%$ of the previous gross salary, plus a fixed sum, or $57.4 \%$ of previous gross salary, whichever is more advantageous. The benefits then decrease over time; the decrease is faster the younger the worker, and the shorter the work experience. For example, a worker who has been working for 4 out of the previous 8 months, gets benefits for 4 months; a worker who has been working for 6 out of the previous 12 months gets 4 months with full benefits, then 3 months at $85 \%$, then nothing, and so on for workers with longer employment histories. In short, workers can alternate between CDDs and unemployment spells, and receive benefits while unemployed.

For our purposes, the history and the specific set of rules regulating CDDs has two main implications:

- One should think of what has happened since the 1980s primarily as an increase in fixed-duration contracts at the extensive margin (an increase in the number of eligible workers and jobs), rather than as an increase in the intensive margin (a decrease in $\left.c_{0}\right) .{ }^{15}$

\footnotetext{
${ }^{15} \mathrm{~A}$ model which formalizes the introduction of CDDs at the extensive margin, and
} 
- The rather stringent rules governing CDDs (conditions, duration, non renewal) imply that, while the proportion of workers under CDDs has increased over time, it has not reached - and, unless rules are changed, will not reach - the levels observed in some other European countries, in particular Spain. ${ }^{16}$

\subsection{Data sources}

Our data, here and in the next section, come from "Enquetes Emploi", a survey of about 1/300th of the French population, conducted annually by INSEE, the French National Statistical Institute.

Questions about CDI versus CDD status are only available from 1983 on, so we only look at the evidence from 1983 to 2000. The design of the survey and the wording of some of the questions were changed in 1990, leading to discontinuities in some of the series in 1990; these discontinuities appear clearly in some of the figures below.

We use the "Enquetes Emploi" to look at the evolution of both stocks and flows. Measures of flows can be constructed in two ways:

- The 3-year panel data structure of the survey allows to follow two thirds of individuals across consecutive surveys, and so to measure their annual transitions. Panel-based transition probabilities ("panel transitions" for short) can be constructed from every year since 1984 on, with one exception: Changes in survey design in 1990 make it impossible to compute transitions for 1990.

which shares some of the features of our model (but was developed independently), is given in Cahuc and Postel-Vinay [2000].

${ }^{16}$ For a description of the nature and the scope of fixed-duration contracts in Spain, and in Italy, see for example Guell-Rotllan and Petrongolo [2000], and Adam and Canziani [1998]. 
- In addition, from 1990 on, the survey includes a question asking for status 12 months earlier. Thus, except for 1999 when the answer to the question has not yet been tabulated, we can also construct retrospective transition probabilities ("retrospective transitions" for short) for each year since $1990 .^{17}$

For our purposes, namely assessing the evolutions (rather than the levels) of transition probabilities over time, it is not clear which approach dominates. As documented by many researchers, transitions based on retro-

spective information are subject to systematic memory biases. ${ }^{18}$ But these memory biases are likely to be fairly stable over time. Panel based transition probabilities suffer instead from some attrition bias. This bias, while smaller, is more likely to change over time: An increase in the proportion of workers with short duration jobs may well lead to an increase in attrition. We therefore remain agnostic and present both the numbers for panel based transitions from 1984 to 2000, and for retrospective information based transitions for 1991 to 2000.

\subsection{Basic evolutions}

As a start, Figure 6 plots the evolution of CDD employment as a proportion of total (salaried) employment, since 1983. It shows how this proportion has increased from $1.4 \%$ of salaried employment in 1983 to $10.8 \%$ in 2000 .

\footnotetext{
${ }^{17}$ The question actually asks for status during each of the previous 12 months, thus allowing for the construction of monthly probabilities - which are closer conceptually to the instantaneous probabilities in the theoretical model. Because of well known issues such as rounding up by respondents, these monthly probabilities are very noisy, and we have not explored these data further.

${ }^{18}$ For more on the differences between the two sets of transition probabilities in the context of Enquetes Emploi, see Magnac and Visser [1999], and Philippon [2000].
} 
Figure 6. Proportion of CDD in employment

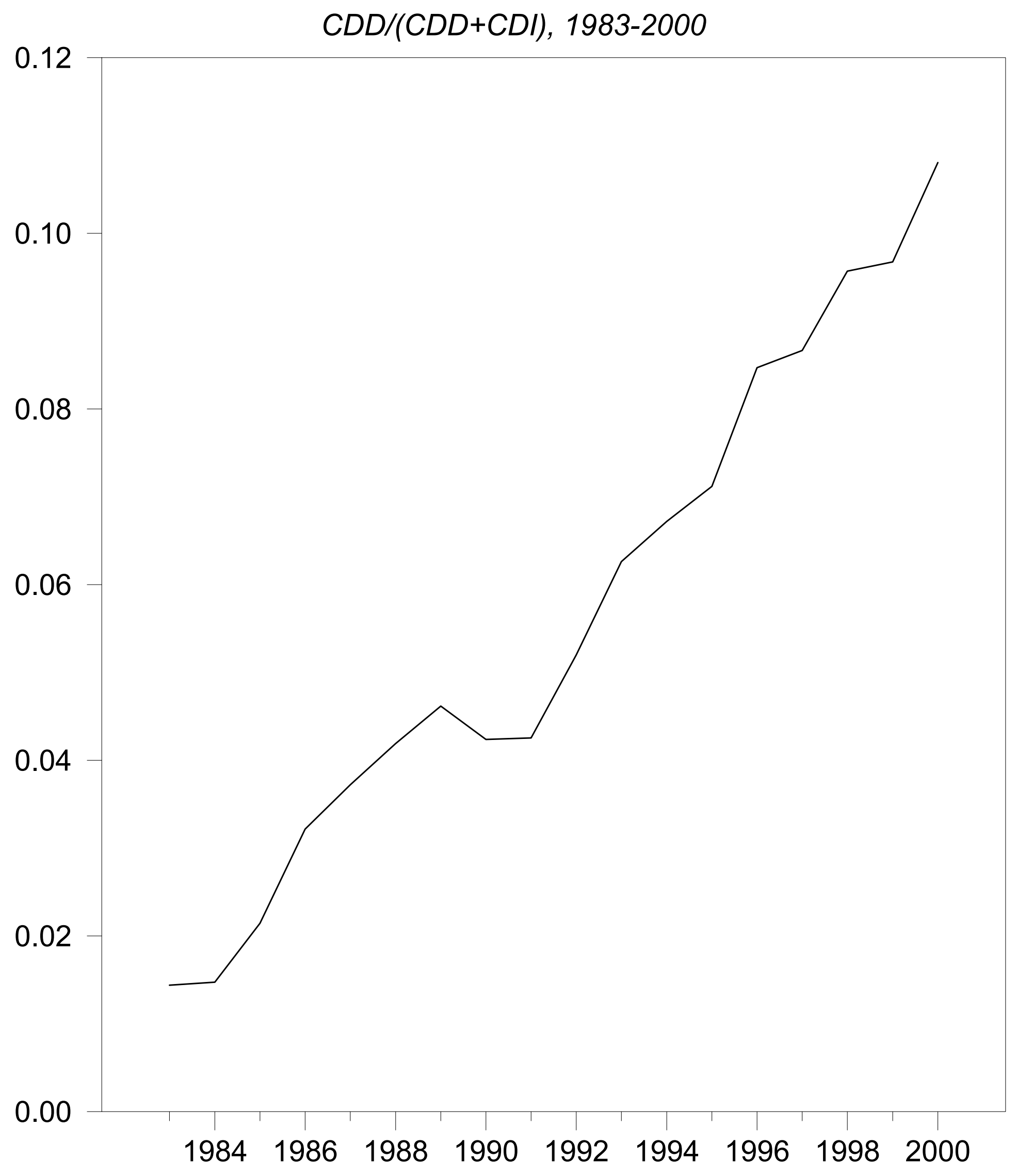


At the same time, the graph makes clear that the specific conditions under which firms can offer CDDs have limited their scope; by contrast, in Spain today, more than $30 \%$ of salaried employment is in the form of fixed-duration contracts.

While the proportion of CDDs in total employment remains limited, the introduction and development of CDDs have completely changed the nature of the labor market for the young. Figure 7 shows the evolution of the proportions of individuals, age 20-24, who are either employed under a CDI, employed under a CDD, or unemployed, or students, from 1983 to 2000. The figure yields a number of conclusions:

- The proportion of students in this age group has increased dramatically, from $21 \%$ in 1983 to $49 \%$ in 2000 . This increase is due in large part to a deliberate policy aimed at increasing the proportion of children taking and passing the baccalaureat (the exam at the end of high school); this proportion has increased over the same period from $28 \%$ to $59 \%$. But it is also a reflection of the poor labor market prospects faced by the young; indeed, as unemployment has decreased since the mid-1990s, so has the proportion of students. This indicates that, for this age group, unemployment numbers should be interpreted with caution.

- The proportion of unemployed in a given 5-year cohort has remained roughly constant, from $15 \%$ in 1983 to $16 \%$ in 1999, and down to $12 \%$ in 2000 (although, because of the steady decrease in participation, the unemployment rate has increased from $20 \%$ in 1983 to $32 \%$ in 1999, and $24 \%$ in 2000).

- Most relevant for our purposes, the proportion of CDIs has sharply dropped while the proportion of CDDs has sharply increased. In 1983, $60 \%$ of a cohort (equivalently $95 \%$ of those employed) were employed under CDIs; in 2000, the proportion was down to $21 \%$ (54\% of those 
Figure 7. CDDs, CDls, Students and Unemployed

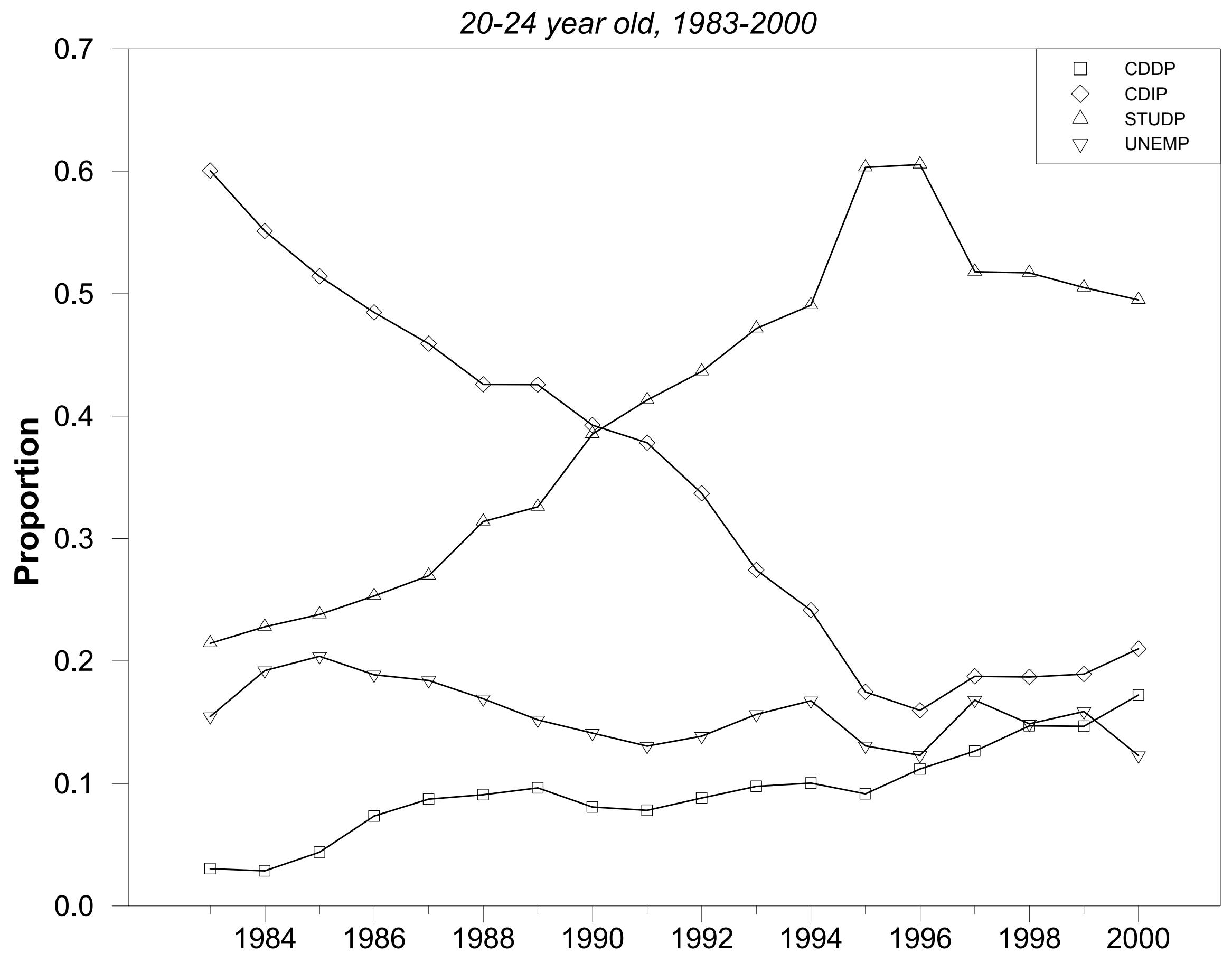


employed). And during the same period, the proportion of those employed under CDDs went from $3.0 \%$ (5\% of employment) to $17 \%$ ( $46 \%$ of employment).

The same qualitative evolution is visible in other age groups, but its quantitative effect decreases across cohorts. The proportion of CDDs has increased from $1.6 \%$ in 1983 to $10 \%$ in 2000 for the $25-29$ cohort, from $1.1 \%$ in 1983 to $6 \%$ in 2000 for the 30-34 cohort, and so on. For this reason, it makes good sense to focus on market evolutions for the 20-24 cohort, and this is what we do in the next section. ${ }^{19}$

\section{Transitions, wages, and utility}

We now look at labor market evolutions for 20-24 year olds, for the period 1983-2000, with the goal of learning something about the effects of CDDs on the labor market. Our approach is descriptive, and its limits are obvious:

First, there has been many other institutional changes in the labor market during that period, from the introduction of a minimum income floor (the RMI), to the reduction in social contributions on low wage workers, to a number of other programs aimed at specific groups in the labor market. ${ }^{20}$ We believe however that, for the group we focus on below, the 20-24 age group, the increase in the proportion of CDDs is indeed the dominant development.

\footnotetext{
${ }^{19}$ We have focused here at differences by age group; one can take other cuts, such as education. One might have expected the proportion of CDDs to decrease with the level of education. This is not the case. In 2000, the proportion of CDDs was roughly the same across education levels, probably reflecting the restrictions under which CDDs can be used by firms.

${ }^{20}$ For a description of some of the programs aimed at the youth, look for example at Fougere et al. [2000].
} 
Second, much of the evolution of unemployment during the period, either for the 20-24 year olds or for the population at large, has been due not so much to institutional changes but to macroeconomic factors. Until recently, this would have raised a very serious identification issue: From the early 1980s to the late 1990s, macroeconomic factors had led to a trend increase in unemployment, making it very difficult to disentangle the effects of that trend from those of the trend increase in CDDs. Fortunately (both for France, and for us), unemployment has started decreasing, so there is now hope of disentangling the two. To see why and how, we start this section by looking at aggregate evolutions.

\subsection{Aggregate evolutions}

The top panel of Figure 8 plots the evolution of the aggregate unemployment rate in France since 1983. The triangles give the evolution of the official unemployment rate (which conforms to the BIT definition); the squares give the evolution of the unemployment rate obtained from Enquetes Emploi. For our purposes, the relevant series (in the sense of a series consistent with the other series we look at below) is that from Enquetes Emploi. That series gives a more pessimistic assessment of the evolution of the labor market in France than the series for the official rate. In 2000, the series implies an unemployment rate of $11.7 \%$, compared to an official rate of $9.7 \%$. The general picture is of a trend increase from 1983 to the mid-1990s, and of a limited decrease since then.

What is relevant to a worker in the labor market is not however the unemployment rate per se, but the probabilities of becoming unemployed if he is currently employed, or of becoming employed if he is currently unemployed. The evolutions of these two transition probabilities are given in the two bottom panels of Figure 8. For each panel, the series with squares gives 


\section{Figure 8. Aggregate labor market conditions, 1983-2000}

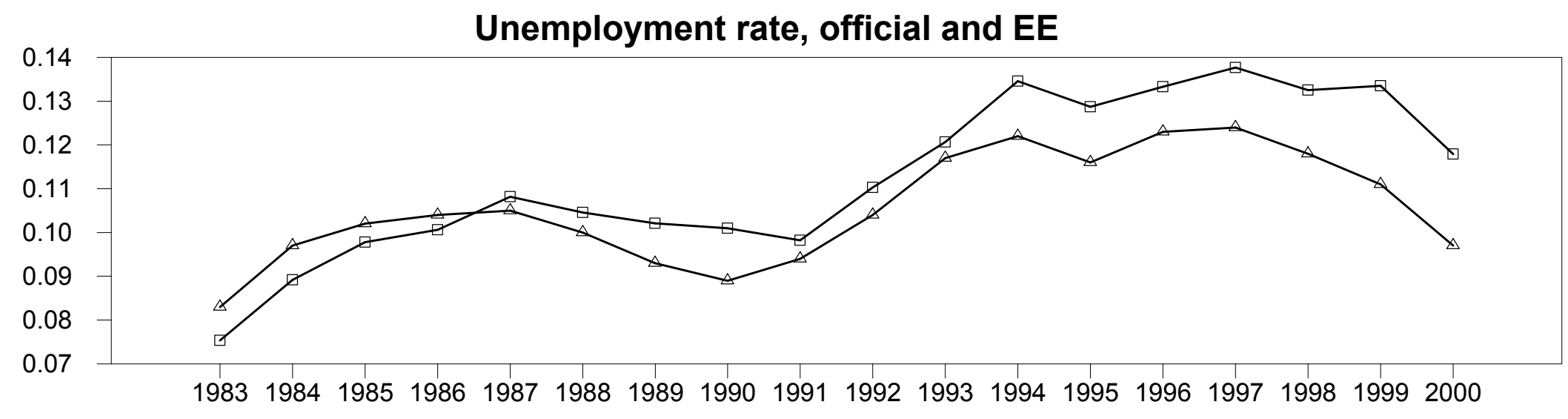

Transition probability from $E$ to $U$
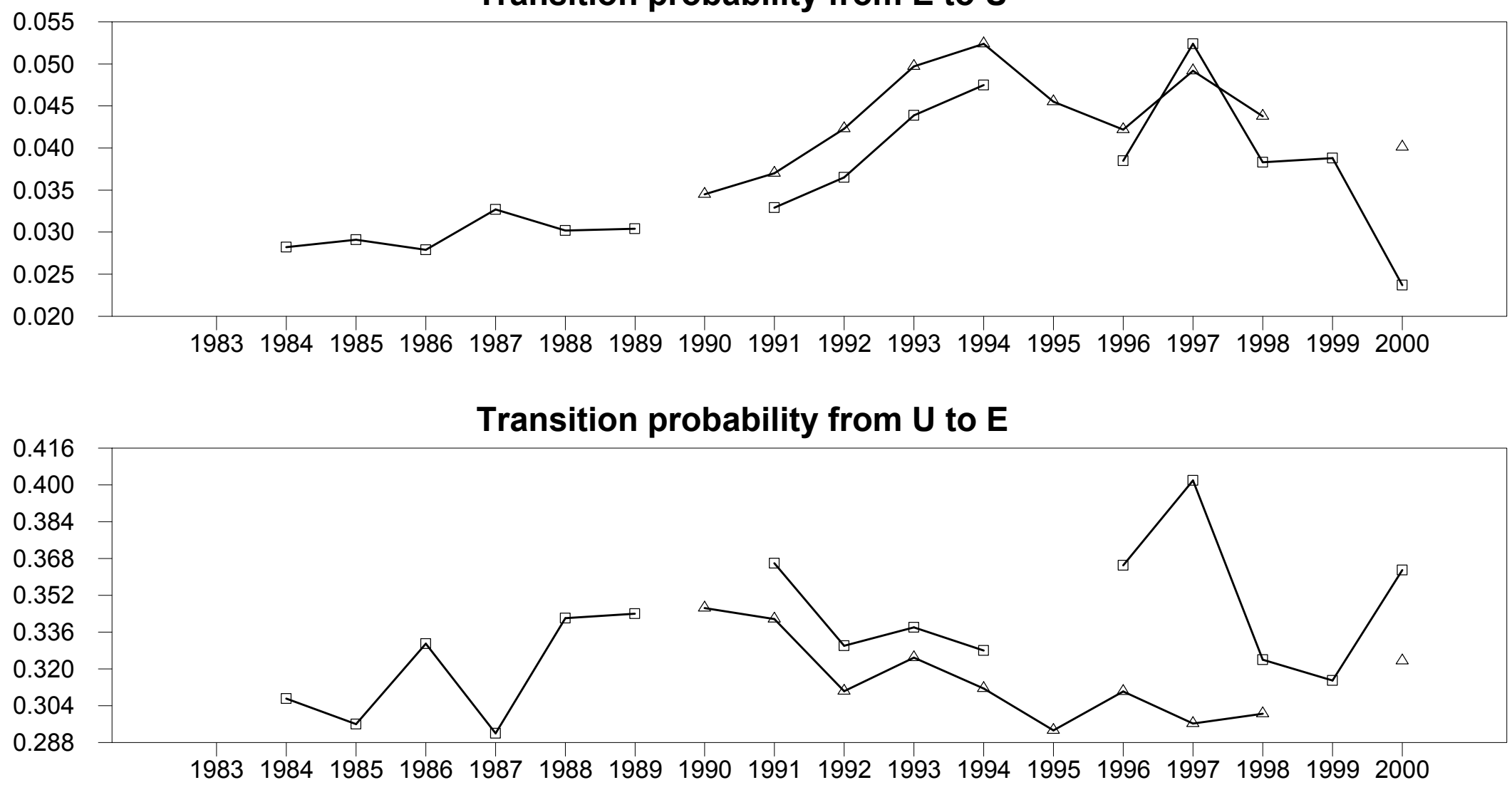
panel transitions, the series with triangles gives retrospective transitions. ${ }^{21}$ We draw two main conclusions from these two panels:

- The 1980s appear different from the 1990s. In the 1980s, the transition probability from employment to unemployment barely increased, and the transition probability from unemployment to employment actually increased. By contrast, in the 1990s, the first transition increased, and the second decreased: The labor market clearly became worse in both dimensions. This worsening surely had a strong effect on the labor market for the 20-24 year olds we focus on below.

- The panel transition from employment to unemployment was lower in 2000 than in any previous year in the sample. The panel transition from unemployment to employment in 2000 was one of the highest in the sample. In other words, despite the fact that the unemployment rate was still high, labor market prospects were, from the point of view of an individual in the labor market, arguably the best since 1984. Thus a comparison of endpoints - 1984 with 2000 - can help us separate out the role of cyclical and structural components. We shall us this below.

\footnotetext{
${ }^{21}$ We discussed earlier why 1990 is missing for panel transitions, and why 1999 is missing for retrospective transitions. Note that 1995 is also missing for panel transitions in Figure 8: The reason is that transitions computed from Enquetes Emploi are very different from those in other years. Most of this is due to a program introduced in that year which subsidized the reemployment of the older long-term unemployed, leading to a very different pattern of flows in 1995. Part of it appears to be due to other problems with the data. We decided to exclude this year here and in most of the graphs below.
} 


\subsection{Transition probabilities for the 20-24 year olds}

Figure 9 gives the evolution of transition probabilities between CDD employment, CDI employment, and unemployment, for 20-24 year olds, from 1984 to 1998. Each of the nine panels plots two series. The first, in black, give panel transitions; the second in grey gives retrospective transitions. Transitions for year $t$ refer to the change in status from March of year $t-1$ to March of year $t$.

We draw three main conclusions from this figure:

- The three left panels show the transition probabilities from unemployment. ${ }^{22}$

The probability of getting a CDI decreases in both subperiods (the 1980s and the 1990s). The probability of getting a CDD increases in both subperiods. Both movements are clearly consistent with the theory.

While the effect is theoretically ambiguous, we saw that the duration of unemployment was likely to decrease as the scope of CDDs increased. The probability of remaining unemployed indeed decreases in the 1980s. But there is no evidence of a further decrease in the 1990s. (Note that the retrospective measure is much higher than the panel measure, but shows the same evolution). In other words, during the 1990s, the higher likelihood of getting a CDD rather than a CDI did not come with an overall increase in the probability of getting a job.

- The three center panels show the transition probabilities from CDD employment.

\footnotetext{
${ }^{22}$ The transition probabilities sum to less than one, as we do not report transitions to self employment, internships, military status, student status, and other non participation.
} 


\section{Figure 9. Transition probabilities. U, CDI, CDD}
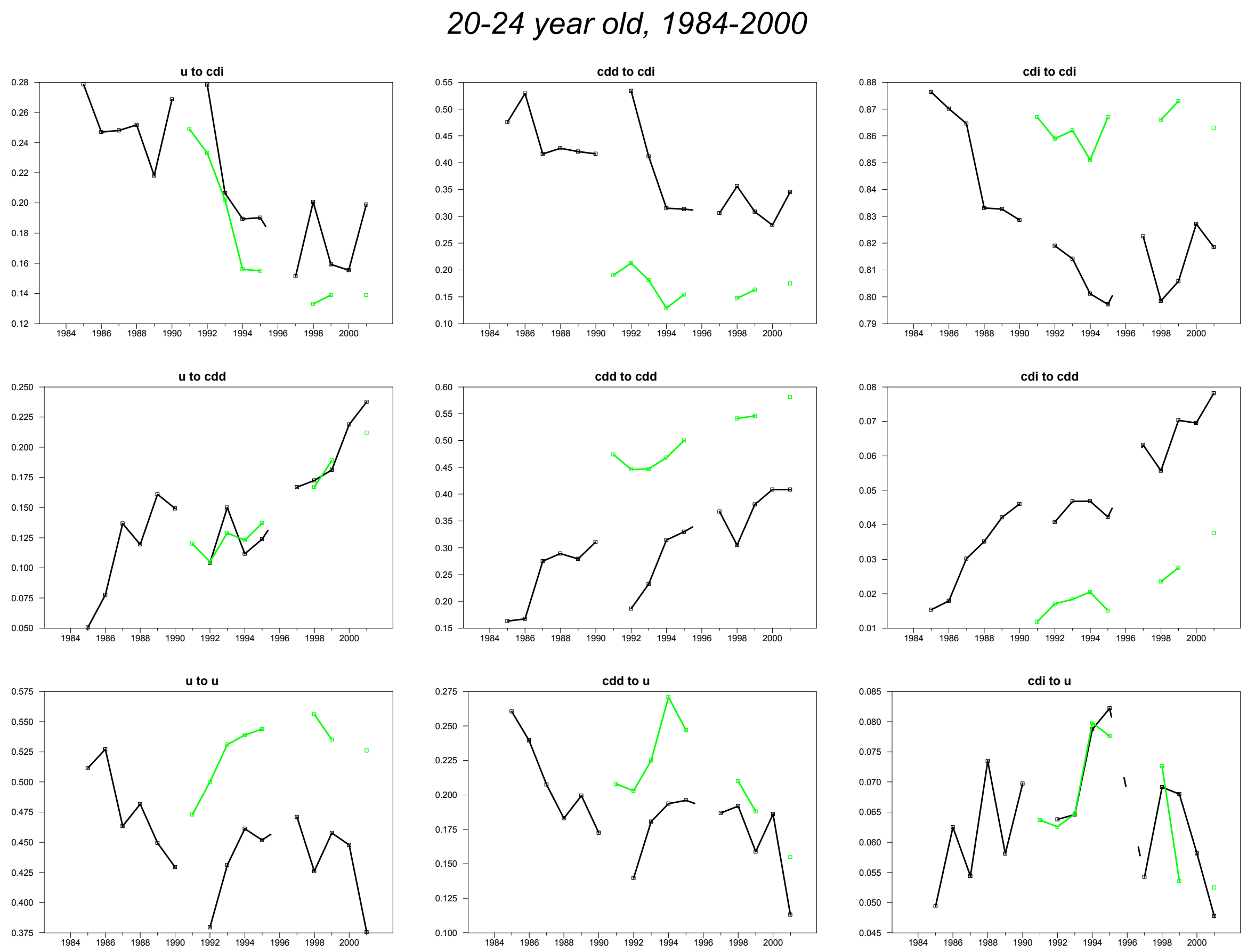
The probability of moving from a CDD to a CDI decreases in each of the two subperiods. The probability of remaining on a CDD (the same or another one) increases throughout the period, nearly doubling in each of the two subperiods (Recall that the level shifts between 1989 to 1991, which are often large in the figure, reflect largely differences in measurement.) Note, again, that while panel and retrospective transitions have rather different levels, their evolution is largely similar over time.

The probability of becoming unemployed decreases steadily in the 1980s. As we look at year-to-year transitions, this presumably reflects the higher probability of finding another job when the current CDD comes to an end. But, again, there appears to be a difference across the two decades. In the 1990s, the transition probability does not exhibit much of a trend.

- The three right panels of Figure 9 show transition probabilities from CDI employment. They are less central to our discussion (indeed in our formal model, these three transition probabilities were all equal to zero, by assumption). One evolution is however worth mentioning. One might have expected that allowing firms to use CDDs would have reduced the flows from CDI employment. The top panel show that this has not been the case: The probability of keeping a CDI has decreased, not increased. This suggests that other factors than changes in firing costs have played a role in determining general trends in separations.

One can construct similar tables for the other age groups. The qualitative features are the same, but the evolutions are more muted the older the age group. We do not report them here.

To summarize: The transition probabilities give a picture of a labor market for 20-24 year olds where the probability of getting a CDD has steadily increased, the probability of getting a CDI has decreased, and the 
probability of staying or becoming unemployed shows no clear trend. In this last dimension, there appears to be a difference across the two decades. The probabilities of becoming unemployed when on a CDD, or remaining unemployed, both decrease in the 1980s, but show no further trend in the 1990s.

\subsection{Expected time to a CDI}

One way of summarizing the information from the transition matrices is to compute the expected time to a CDI starting from different labor market positions.

To compute these expected times, we use, for each year, the estimated transition matrix obtained using either panel data or retrospective information, based on eight different states (CDI, CDD, unemployed, self employed, student, intern, army, other non participation), for 20-24 year olds. Note that this computation assumes static expectations in two dimensions. First it assumes that future transition probabilities for 20-24 year olds will be the same as this year's. Second, it ignores the fact that, as those currently 20 to 24 become older, the relevant transition probabilities will become those

relevant for the 25 to 29 year olds, and so on. This second bias leads to an overestimation of the level of expected times to a CDI. But what we care about here are changes over time, and this simple approach is likely to capture them.

The evolution of expected times for the 20-24 age group, starting either from a CDD or from unemployment, is plotted in Figure 10.

Starting from a CDD, the expected time to a CDI appears roughly constant in the 1980s. Starting from unemployment, the expected time decreases slightly. This is the result of two offsetting changes: On the one hand, a decreased probability of getting a CDI starting either from unemployment or from a CDD, leading to an increase in the expected time. On 
Figure 10. Expected time to a regular job
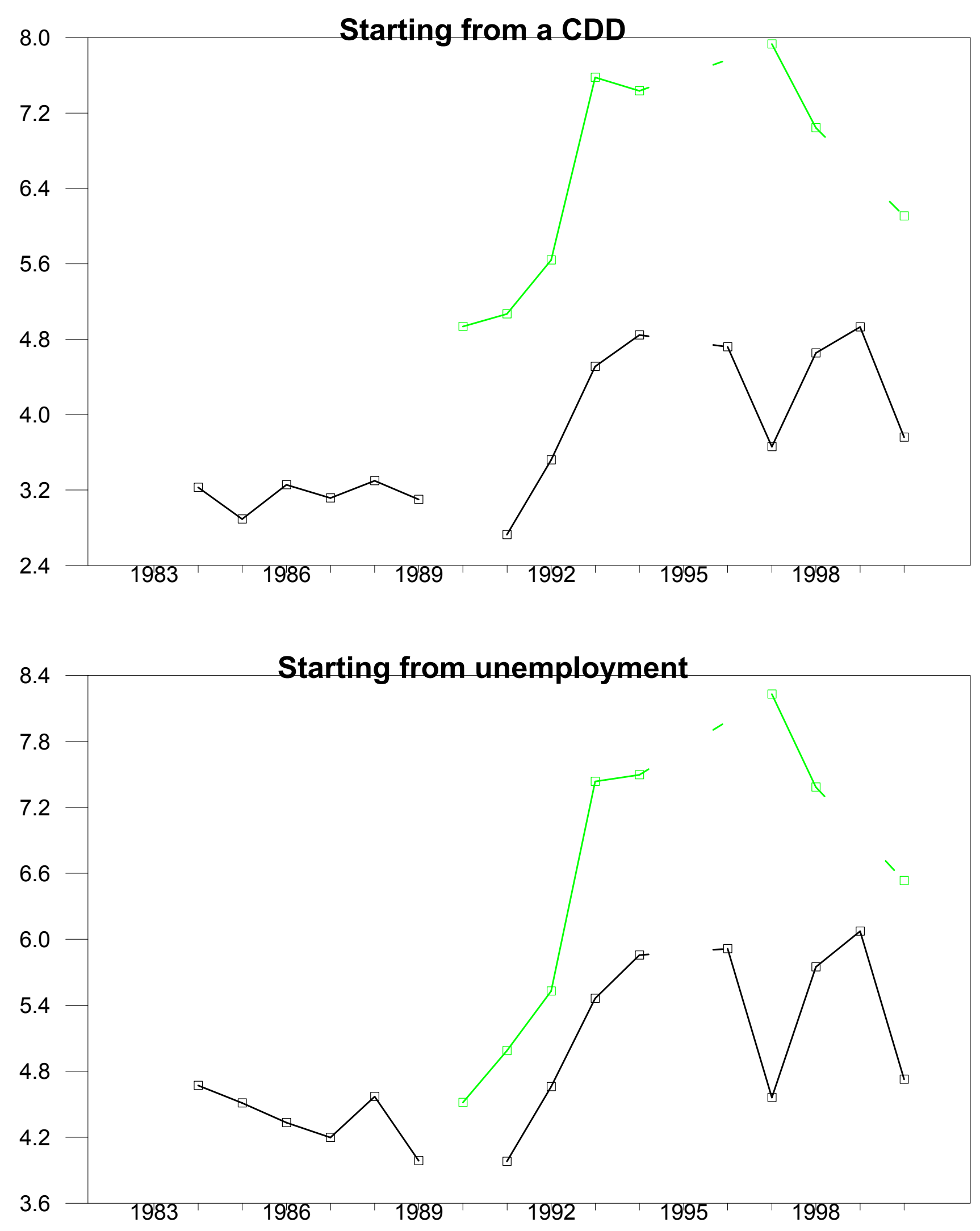
the other, an increased probability of getting a CDD when unemployed, together with a higher probability of getting a CDI starting from a CDD than starting from unemployment. In the 1980s, the two effects roughly cancel each other.

The picture is different in the 1990s, where the expected time increases significantly until the late 1990s, declining partially thereafter. While the expected time based on retrospective information is higher than the expected time based on panel data, both series go up during the period. The expected time from unemployment based on retrospective information increases from 4.8 years in 1990 to 8.2 years in 1996 , to decline to 6.5 years in 2000 ; its panel data counterpart goes from 4.0 to 6.0, down to 4.7 years in 2000 .

\subsection{Wages}

A complete picture requires looking also at wages. To do so, we run a standard wage regression, regressing for each year, from 1983 to 2000, the logarithm of the monthly net wage on a set of controls - education (15 categories), age (10 categories) and a dummy equal to 1 if the worker is on a CDD, 0 if on a CDI. Thus, we run, for each year:

$$
\log w_{i}=X_{i} \beta+b D+\epsilon_{i}
$$

Figure 11 plots the time series of estimated $b$ 's, from estimation of the wage equation for each year from 1983 to 1998. Given age and education, CDDs appear to pay about $20 \%$ less than CDIs. The evidence suggests also that the gap between the two wages has increased over time, from $12 \%$ in 1983 to $29 \%$ in 1993 , and to $22.5 \%$ in 2000 .

How should we interpret this decrease in the relative wage over time? In our model, partial reform has two effects on the wage of CDDs relative to CDIs: The first is a decrease in the bargaining power of CDDs, leading to a decline in their wage. The second is a decline in bonding, in how low a 
Figure 11. Wage discount for CDDs, with controls

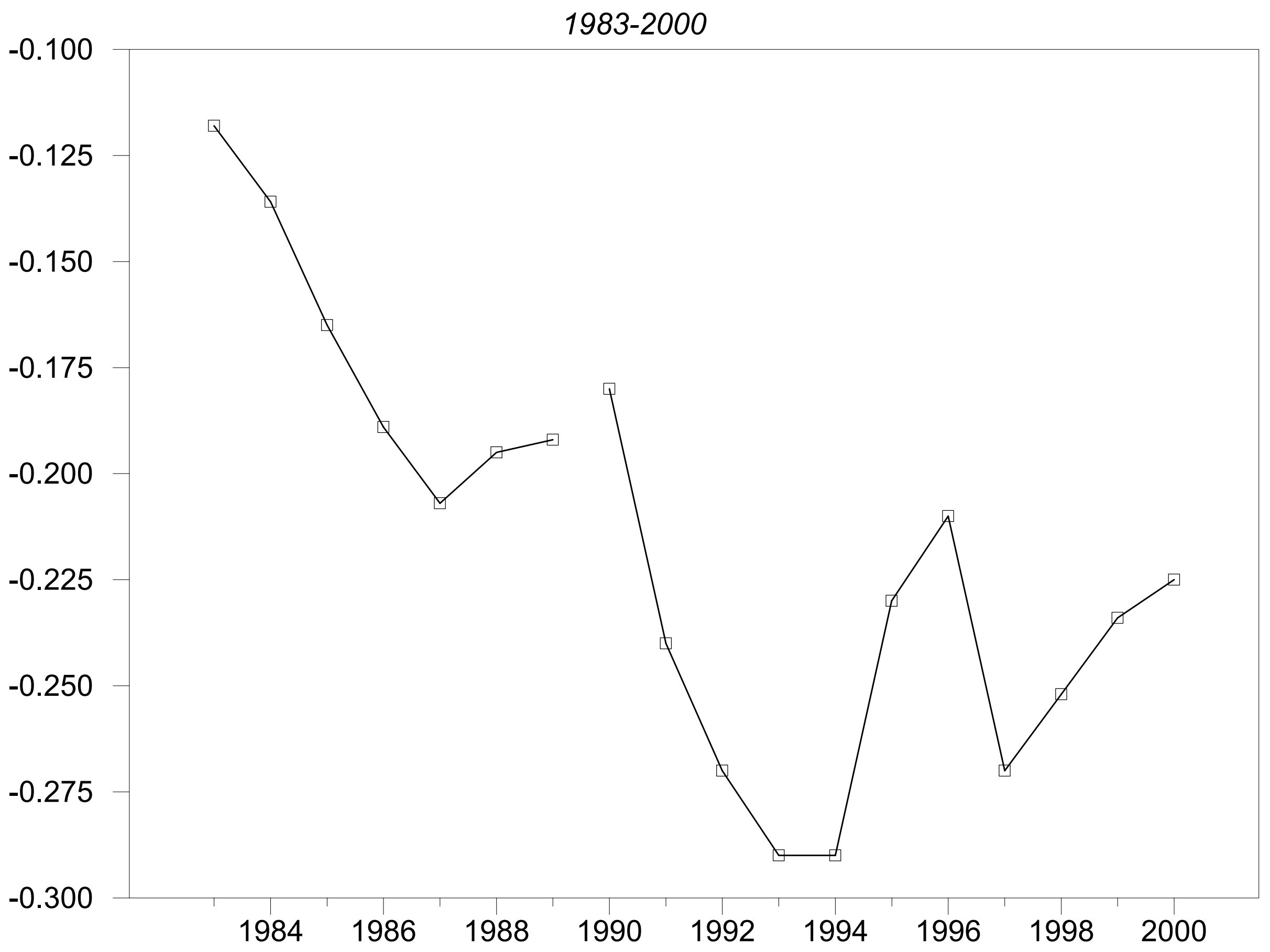


wage entry-level workers are willing to accept in order to have a chance at a regular job. In our model also, a decrease in the relative wage for entry-level jobs, is necessarily associated with an increase in $V^{u}$. The intuition for this is that if the wage goes down, the decline in bonding is small, the effect of reform on actual and excess turnover is limited, so the reform increases welfare.

Thus, if the economy conformed to our model, the finding that the wage has decreased would be prima facie evidence that partial reform has been welfare improving. There is however one important difference between our model and reality: In our model, all entry-level jobs have the same productivity. This is not the case in reality, and there is a plausible argument that what has happened over time is the extension of the use of CDDs to jobs or to workers with lower productivity. If this is the case, the decrease in the wage we observe in the data may be due neither to bonding or bargaining, but to a change in the nature of CDD jobs or CDD workers over time. We expand on this point in the conclusion.

\subsection{Values}

In our model, the welfare effects of partial reform are captured by what happens to $V^{u}$, the expected present value of utility if currently unemployed. It is tempting to construct an empirical counterpart and see how it has evolved over time. This is what we do in this last subsection. More specifically, because not all entrants enter as unemployed, we construct not $V^{u}$, but the average value $\bar{V}$, the average expected present value of utility for a 20-24 year old, and look at its evolution over time.

The results of this exercise must obviously be interpreted with more than a grain of salt: There are many assumptions and many steps involved in the construction of $\bar{V}$, all likely to imply substantial measurement error. Nevertheless, we think this provides a rather transparent way of summarizing 
what we have seen about the evolutions of transition probabilities and wages in a single statistic.

To compute $V^{i}$, the expected present value of utility if currently in state $i$, we proceed as follows. Let $V^{i}$ be the expected present value of utility conditional on being in state $i$ today. We consider five states in our computation (CDI, CDD, unemployed, intern, self employed). ${ }^{23}$ Let $V$ be the associated vector of utilities associated with the different states. Let $A$ be the transition matrix associated with these different states. Let $w$ be the vector of wages or wage equivalents associated with each state. Then, we construct $V$ as:

$$
V=w+\frac{1}{1+r} A V
$$

Or equivalently,

$$
V=\left(I-\frac{1}{1+r} A\right)^{-1} w
$$

$\bar{V}$ is then constructed as:

$$
\bar{V}=\sum p_{i} V_{i}
$$

where the $p_{i}$ are the proportions of individuals in state $i$, and sum to one, and $V_{i}$ are the elements of $V$.

We focus on the 20-24 age group. For $A$, we use for each year the es-

\footnotetext{
${ }^{23}$ Note that we exclude three states: student, army, and out of the labor force. If these states were included, our results would be much stronger (i.e show a larger decline in $\bar{V}$.) This is because, if the flow utility of being a student is assumed to be low relative to the wage, the increase in the proportion of students would dominate the series, and lead to a large downward trend in $\bar{V}$. This trend however would be largely unrelated to the issue at hand, namely the role of CDDs.
} 
timated transition matrix obtained using either panel data or retrospective information. Just as for the construction of expected times earlier, this computation assumes static expectations in two dimensions, i.e. an unchanged value of the matrix for a given age group over time, and an unchanged transition matrix as individuals in the group get older. The justification is simplicity, and our belief that, as evolutions are qualitatively similar across age groups, this should capture the relevant trends.

For $w$, we normalize the CDI wage to 1 (i.e. we ignore general wage growth over time). We take the CDD wage to be equal to 1 minus the discount shown in Figure 11 for each year. Based on unemployment benefit rules, we use a value of 0.5 for the wage equivalent when unemployed. Because the transition probabilities to other states are small, the other elements of $w$ play little role in the results; we assume a value of 1 for self employment income, a value equal to the CDD wage for internships. We use an annual interest rate of $12 \%$.

The results are presented in the top panel of Figure 12. The black line gives the series for $\bar{V}$ using panel transitions, the grey line gives the series using retrospective transitions.

The general impression is one of little change in the 1980s, followed by a steady worsening until the late 1990s, and a partial improvement at the end. According to this measure, (and leaving aside the general increase in real wages over time), the average welfare of the 20-24 year old is slightly lower in 2000 than it was either in 1984, or (and this comparison is safer given the changes in the survey in 1990) than in $1991 .^{24}$

Can we conclude from this that the effects of CDDs have been perverse? The answer is obviously not. Many other factors have been relevant during

\footnotetext{
${ }^{24}$ Another finding, not reported here, is how much closer $V_{C D D}$ is to $V_{U}$ than to $V_{C D I}$. In that sense, the French labor market has become increasingly dual.
} 
Figure 12. Values

1984-2000
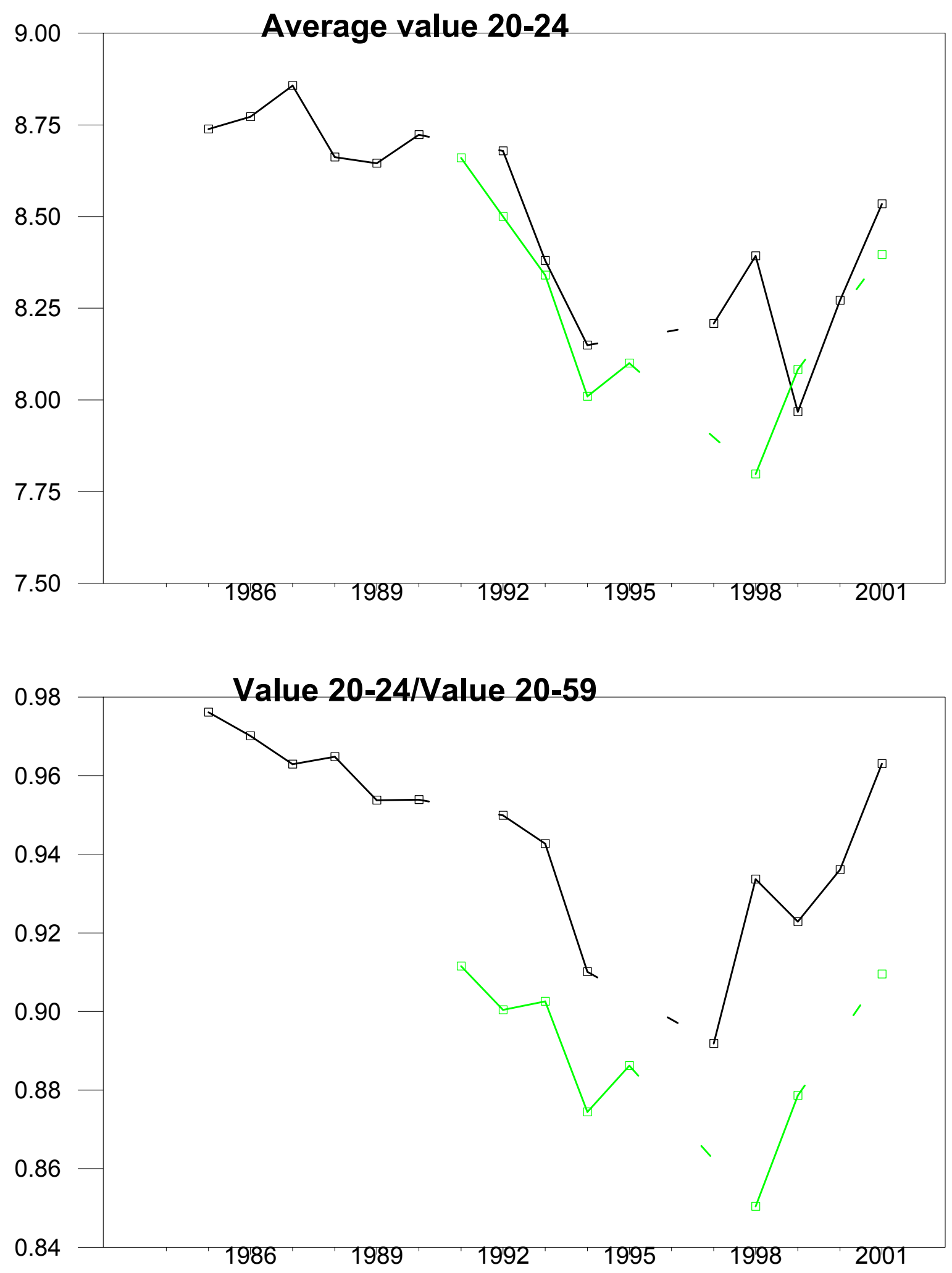
that period, and attributing all the change in $\bar{V}$ to the introduction of CDDs would obviously be wrong. But we can make some progress:

Clearly much of the decrease in $\bar{V}$, especially in the 1990s, must have been due to macroeconomic factors, rather than to the increase in the proportion of CDDs. But here, the evidence from year 2000 is helpful. As we saw earlier, in terms of aggregate transition probabilities, 2000 is arguably the best year of the sample. Yet, in that year $\bar{V}$ is still lower than it was in either 1984, or 1991. In short, the lower value of $\bar{V}$ in 2000 cannot easily be attributed to macroeconomic factors.

We can actually go one step further. Some of the changes in $\bar{V}$ are likely to reflect structural changes in the labor market other than CDDs, changes which might affect all cohorts. In that case, attributing the decline in $\bar{V}$ over the sample to the introduction of CDDs would clearly be wrong. This suggests looking not at the evolution of the average value $\bar{V}$ for the 20-24 age group, but rather at the evolution of this average value relative to the average value for the whole labor force - which is much less affected by the introduction of CDDs.

With this motivation, we plot the evolution of the ratio of the average value for the 20-24 age group to the average value for the 20-59 age group in the bottom panel of Figure 12 (We use the same wages for both groups, thus not taking into account the age profile of wages in computing the two values. This would change the level, but not the evolution, of the ratio over time). The graph has two main characteristics. First, a nearly continuous decline in the relative value from 1984 to 1997. Then an increase, but to a lower level than at the start of the sample.

This suggests to us two conclusions. First, much of the evolution of the relative value for the $20-24$ age group reflects aggregate evolutions, the long worsening and the recent improvement in the labor market: The young suffer more in a depressed labor market. Second, the fact that the value remains lower in 2000 suggests that more has been at work. The extension of 
CDDs, which disproportionately affects that group, is a plausible candidate explanation for this underlying deterioration. Put more conservatively, there is no evidence that the introduction and development of CDDs has improved the relative welfare of those most affected by it, namely the young.

\section{Conclusions}

We have looked at the effects of the introduction of fixed-duration contracts.

On the theoretical side, we argued that the effects of such partial reform may be perverse, leading to higher turnover, and possibly lower welfare: The excess turnover induced by the forced coexistence of fixed-duration and regular contracts can be high enough to offset the efficiency gains of improved flexibility.

On the empirical side, we looked at the evolution of labor market evolutions for young workers in France since 1983. We found strong evidence of increased turnover, and argued that, if anything, the effect of the fixed duration contracts on the welfare of young workers appears to have been negative.

If our theoretical and empirical conclusions are valid, this suggests that, at least from an economic viewpoint (i.e leaving aside political economy implications), such partial reform may be a very poor substitute for broader reform, i.e. an across the board reduction in firing costs for all workers.

Many questions remain open for future research. To us, the most important may be how such a reform affects the nature of the jobs offered to workers. We have assumed in our model that contracts had no impact on the nature of the jobs created by firms. There are good theoretical and empirical reasons to think they may. There are two potential effects at work (which parallel the two effects at work on firms' decisions in our model). On the one hand, lower costs on fixed-duration contracts give more incentives for firms to take more risks, design jobs which, associated with the right worker, lead 
to high productivity. On the other, lower costs on fixed-duration contracts may instead induce firms to design routine, low productivity jobs, which they can fill through the use of fixed-duration contracts. The wage evidence we reviewed in our paper suggests that this second effect might indeed be at work. 


\section{References}

Adam, P. and Canziani, P., 1998, Partial de-regulation: Fixed-term contracts in Italy and Spain, CEP DP 386.

Blanchard, O. and Portugal, P., 2001, What hides behind an unemployment rate. Comparing Portuguese and U.S. unemployment, American Economic Review, forthcoming.

Caballero, R. and Hammour, M., 1996, The 'fundamental transformation' in macroeconomics, American Economic Review 86(2), 181-186.

Cahuc, P. and Postel-Vinay, F., 2000, Temporary jobs, employment protection, and labor market performance, mimeo Cepremap, Paris.

Fougere, D., Kramarz, F., and Magnac, T., 2000, Youth employment policies in France, CEPR DP 2394.

Guell-Rotllan, M. and Petrongolo, B., 2000, Workers' transitions from temporary to permanent employment: The Spanish case., CEP DP 438.

Lamy, 2000, Lamy Social, Editions Lamy, Paris.

Lazear, E., 1990, Job security provisions and employment, Quarterly Journal of Economics 105-3, 699-726.

Liberation, 2000, Interviews of workers on CDDs, May 2, Special Emploi.

Magnac, T. and Visser, M., 1999, Transition models with measurement errors, Review of Economics and Statistics 81-3, 466-474.

OECD, 1999, OECD Employment Outlook, OECD.

Philippon, T., 2000, Memory management, mimeo MIT.

Poulain, G., 1994, Les contrats de travail à durée déterminée, Litec; Paris, France.

Saint-Paul, G., 1996, On the political economy of labor market flexibility, NBER Macroeconomics Annual 8, 151-196. 
Saint-Paul, G., 2000, The Political Economy of Labor Market Reforms, Oxford University Press, Oxford, forthcoming.

Shapiro, C. and Stiglitz, J., 1984, Equilibrium unemployment as a discipline device, American Economic Review 74, 433-444. 